\title{
Subcutaneous Administration of Angiotensin-(1-7) Improves Recovery after Traumatic Brain Injury in Mice
}

\author{
Zachary C. Janatpour, ${ }^{1}$ Alexandru Korotcov, ${ }^{2}$ Asamoah Bosomtwi, ${ }^{2}$ \\ Bernard J. Dardzinski, ${ }^{2,3}$ and Aviva J. Symes ${ }^{1}$
}

\begin{abstract}
Angiotensin II (Ang II)-mediated activation of its type I receptor (AT1R) in the central nervous system promotes glial proliferation, local inflammation, and a decrease of cerebral blood flow. Angiotensin-(1-7) (Ang-(1-7)) —an Ang II derivative peptide-signals through the Mas receptor (MasR) in opposition to Ang II/AT1R, promoting anti-inflammatory, vasodilatory, and neuroprotective effects. As our laboratory has previously demonstrated beneficial effects of AT1R inhibition following controlled cortical impact (CCI) in mice, we asked whether activation of Ang-(1-7)/MasR signaling would also be beneficial in this model. Adult male C57BL/6 mice were injured by CCI. Ang-(1-7) or vehicle was administered subcutaneously (S.Q.) at $1 \mathrm{mg} / \mathrm{kg} / \mathrm{day}$ at 1 or $6 \mathrm{~h}$ post-injury, until animals were sacrificed at 3 or 29 days post-injury (dpi). Ang-(1-7) attenuated motor deficits at 3 dpi and improved performance in the Morris Water Maze at 28 dpi. Brain histology or magnetic resonance imaging (MRI) indicated that Ang-(1-7)-treated mice had smaller lesion volumes at 3, 10, 24, and 29 dpi. Pre-treatment with A779, a MasR antagonist, prevented Ang-(1-7) from reducing lesion volume at $3 \mathrm{dpi}$, suggesting that the benefits of Ang-(1-7) were MasR-dependent. Immunohistochemistry revealed that Ang(1-7) reduced microgliosis at 3 and $29 \mathrm{dpi}$, and astrogliosis at $29 \mathrm{dpi}$. Ang-(1-7) decreased neuronal and capillary loss at $29 \mathrm{dpi}$. In summary, S.Q. administration of Ang-(1-7) after injury had anti-inflammatory, neuroprotective, and cerebrovascularprotective actions leading to improved functional and pathological recovery in a mouse model of traumatic brain injury (TBI). These data show for the first time that Ang-(1-7) has potential therapeutic use for TBI.
\end{abstract}

Keywords: angiotensin-(1-7); controlled cortical impact; Mas receptor; renin-angiotensin system; traumatic brain injury

\section{Introduction}

$\mathbf{T}$

Raumatic Brain InJURy (TBI) is a leading cause of death and disability worldwide. ${ }^{1}$ Current medical and surgical management of acute TBI patients focuses on prophylactic measures to decrease intracranial pressure and seizure frequency, with other treatments addressing symptoms rather than injury. ${ }^{2}$ Over 30 clinical trials, with more than half testing specific pharmacologic agents, have failed to show efficacy in TBI. ${ }^{3}$ The lack of treatment options in TBI underlies the need to develop and test novel neuroprotective agents.

TBI pathophysiology is classically divided into two components: primary and secondary. The primary injury constitutes immediate tissue destruction resulting from the mechanical force of impact to the brain. ${ }^{4}$ This includes shearing of axons and blood vessels, as well as disruption of cell membranes, resulting in the uncontrolled expulsion of intracellular contents and blood into the brain parenchyma. ${ }^{4}$ Secondary injury refers to cell death and parenchymal damage caused by cellular, molecular, and physiologic cascades initiated by the primary insult. These cascades involving inflammation, oxidative stress, excitotoxicity, glial proliferation, and disrupted cerebral blood flow can exacerbate the existing damage. ${ }^{4,5}$ The ability to pharmacologically mitigate these cascades has the potential to reduce secondary injury, and ultimately improve functional outcomes.

Within the central nervous system (CNS), activation of angiotensin II type 1 receptor (AT1R), by its ligand angiotensin II (Ang II), increases inflammation, fibrosis, and oxidative stress, and decreases cerebral blood flow following ischemic stroke. ${ }^{6,7}$ Collectively, these factors potentiate the neuronally hostile poststroke environment, with deletion of AT1R improving recovery after ischemic stroke in mice. ${ }^{7-10}$ Similar to these stroke studies, our laboratory and others have demonstrated that deletion of AT1R or pharmacologic antagonism of the AT1R with angiotensin II receptor blockers (ARBs) protects mice against molecular, cellular, and functional consequences of TBI. ${ }^{1-13}$ These data demonstrate that activation of the AT1R is detrimental to recovery after TBI in mice and suggest that the endogenous brain angiotensin system exacerbates the deleterious sequelae of TBI. ${ }^{11-13}$

${ }^{1}$ Department of Pharmacology and Molecular Therapeutics, Program in Molecular and Cell Biology, ${ }^{2}$ Translational Imaging Core, Center for Neuroscience and Regenerative Medicine, ${ }^{3}$ Department of Radiology and Radiological Sciences, Uniformed Services University, Bethesda, Maryland. 
Within the last 20 years, a novel protective axis of the reninangiotensin system (RAS) has been characterized. ${ }^{14}$ The major ligand of this axis, a seven amino-acid peptide known as angiotensin-(1-7) (Ang-(1-7)), is cleaved from Ang II by the actions of angiotensin converting enzyme 2 (ACE2). ${ }^{15-17}$ Ang-(1-7) has low affinity for AT1R, and instead acts as the ligand to a G-protein coupled receptor known as the Mas receptor (MasR). ${ }^{18,19}$ Ang-(1-7) signaling through the MasR promotes vasodilation and decreases inflammation, fibrosis, as well as oxidative stress-actions largely in opposition to those initiated by AT1R signaling. ${ }^{14,20-23}$ Ang-(1-7) directly exerts an antiinflammatory effect on both microglia and astrocytes and is neuroprotective, even in the absence of astroglia. ${ }^{14,20-23}$ Consequently, therapeutic benefits of increased Ang-(1-7) have been demonstrated in various rodent models of CNS damage, including ischemic and hemorrhagic stroke and LPS-induced brain injury. ${ }^{24-29}$ As antagonism of the AT1R or agonism of MasR is beneficial in stroke models and we have shown that antagonism of the AT1R improves recovery in TBI models, we hypothesized that Ang-(1-7) could be beneficial in a rodent model of TBI. ${ }^{11,13,25,27,28,30}$ In this study, we have determined the effects of post-injury subcutaneous (S.Q.) administration of Ang-(1-7) on recovery from controlled cortical impact (CCI) injury in mice.

\section{Methods}

\section{Animals}

All animal studies were approved by the Uniformed Services University of the Health Sciences Institutional Animal Care and Use Committee and were conducted in accordance with the National Research Council guide to the Care and Use of Laboratory Animals. C57BL/6NCr male mice (NCI, Frederick, MD), ranging in age from 8-10 weeks and weighing $20-25 \mathrm{~g}$, were utilized for each experiment. All mice were kept under 12:12 h light and dark cycle with access to food and water ad libitum. Five mice were housed in each cage. After arrival, mice were acclimatized for 1 week before use.

\section{Controlled cortical impact injury}

Mice were anesthetized with isoflurane (3\% induction, $2 \%$ maintenance) and their heads mounted in a sterotaxic frame. Body temperature was maintained for the duration of surgery using an isothermal heating pad (Stoelting, IL). Scalps were shaved over the designated area, and cleansed with $70 \%$ ethanol followed by Betadine. Eyes were protected with ointment (Optixcare Eye Lube). A 1-cm midline scalp incision was made to expose bregma, the pericranium reflected, and a $3 \mathrm{~mm}$ craniectomy made $(2 \mathrm{~mm}$ lateral [left], $2 \mathrm{~mm}$ caudal to bregma). An electromagnetically driven CCI injury device (Impact One stereotaxic impactor; Leica Microsystems, Germany) was used to deliver a severe CCI (impact depth $2 \mathrm{~mm}$, speed $3.6 \mathrm{~m} / \mathrm{sec}$, dwell time $100 \mathrm{msec}$ ) at a $12^{\circ}$ angle to the dura mater. The scalp was sutured-closed. Sham-animals received the same anesthesia and scalp incision without craniectomy or impact injury.

\section{Drug treatment}

All treatments were administered either by subcutaneous injection (daily $250 \mu \mathrm{L}$ bolus) or continuous infusion via subcutaneously implanted micro-osmotic pumps (Alzet, Model 1004, delivering $0.11 \mu \mathrm{L} / \mathrm{h}$ ). Ang-(1-7) (TXA-127; a gift from Constant Pharmaceuticals, Boston, MA) was suspended in bacteriostatic saline (Hospira, Lake Forrest, IL; RL-4471) at concentrations of $10.0 \mathrm{mg} / \mathrm{mL}$ for micro-osmotic pumps and $0.1 \mathrm{mg} / \mathrm{mL}$ for injections, ensuring $1.0 \mathrm{mg} / \mathrm{kg} /$ day by either form of administration. Mice that were sacrificed at 3 days post-injury (dpi) received daily injections starting $1 \mathrm{~h}$ post-injury (hpi). Mice that were sacrificed at $29 \mathrm{dpi}$ received a one-time injection at $6 \mathrm{hpi}$ followed by micro-osmotic pump implantation at $24 \mathrm{hpi}$. The pumps were primed with Angiotensin-(1-7) for $48 \mathrm{~h}$ before implantation. Mice treated with the Mas antagonist A-779 were implanted with micro-osmotic pumps starting 2 days prior to CCI. Pumps were primed with A-779 (Tocris Bioscience, Bristol, UK; 5937) at $25.0 \mathrm{mg} / \mathrm{mL}$ in bacteriostatic saline, ensuring administration of $2.5 \mathrm{mg} / \mathrm{kg} / \mathrm{day}$. These mice then received daily injection of Ang-(1-7) or saline, starting at $6 \mathrm{hpi}$, until sacrifice at $3 \mathrm{dpi}$.

\section{Experimental design and randomization}

The overall experimental design is presented in Figure 1. For histology experiments, we used between 5-10 mice/group. For behavioral studies we included 18-20 mice/group. Less than $2 \%$ of the injured mice died prematurely after surgery. Three mice were excluded post hoc during lesion volume analysis due to predetermined measurement criteria (see histological lesion volume calculations in the Methods section, Cresyl violet staining and histological lesion volume measurements subsection, on the next page). Treatment of drug or vehicle was randomly assigned and administered to each mouse, with the investigator blinded to the treatment. Blinding was not undone until post hoc data analysis concluded. The investigator treated control mice similarly.

\section{Rotarod}

Motor coordination was assessed by ability to stay on a rotating rod. Mice were trained and tested 3 days prior to injury and tested again at 1 and $3 \mathrm{dpi}$. The rod was accelerated from 4 to $60 \mathrm{rpm}$ over $2 \mathrm{~min}$ and held at $60 \mathrm{rpm}$ for an additional $2 \mathrm{~min}$. The time the mice were able to stay on the rod (latency to fall) was recorded in seconds. Mice who did not fall received a maximum time of $240 \mathrm{sec}$.

\section{Morris Water Maze}

Spatiotemporal learning and memory deficits were assessed daily from 24 to 28 dpi via the Morris Water Maze (MWM) as previously described. ${ }^{13,31}$ A $1.5-\mathrm{m}$ diameter basin was filled to $30 \mathrm{~cm}$ with $25^{\circ} \mathrm{C}$ tap water. Four $60 \mathrm{sec}$ trials were performed each day for each mouse, with $4 \mathrm{~min}$ of rest between each trial, for 5 consecutive days. The time to reach and stay on the submerged platform for $15 \mathrm{sec}$ (located in the northwest tank quadrant) was recorded as latency to reach platform. On training Day 5 (at $28 \mathrm{dpi}$ ), $1 \mathrm{~h}$ after the last training trial, a probe trial was performed where mice were placed in the tank for $60 \mathrm{sec}$ with the platform removed. The time spent in the northwest quadrant and average swim speed were recorded using ANYmaze tracking software (Stoelting, IL).

\section{Tissue preparation for histological/immunohistochemical analysis}

Mice were sacrificed at 3 and 29 days after CCI injury. Mice were anaesthetized with ketamine/xylazine (intraperitoneal injection, $100 \mathrm{mg} / \mathrm{kg}$ ketamine, $12.5 \mathrm{mg} / \mathrm{kg}$ xylazine) and intracardially perfused with $0.9 \%$ saline followed by $4 \%$ paraformaldehyde. Brains were removed and placed in $4 \%$ paraformaldehyde overnight at $4^{\circ} \mathrm{C}$. The brains were then transferred into $10 \%$ sucrose solution and again stored overnight at $4{ }^{\circ} \mathrm{C}$. This transfer and storage process was repeated with $20 \%$ and $30 \%$ sucrose. Following overnight storage in $30 \%$ sucrose, brains were frozen in $-78.5^{\circ} \mathrm{C}$ isopropyl alcohol, then removed from the isopropyl alcohol and stored at $-80^{\circ} \mathrm{C}$ until sectioning. Upon sectioning, brains were allowed to warm to $-22^{\circ} \mathrm{C}$ and cut into $20-\mu \mathrm{m}$ coronal sections by cryostat. Brain sections were stored in Olmo's cryopreservant at $-20^{\circ} \mathrm{C}$. Brain sections spanning the lesion site were selected for histological and immunohistochemical analysis (approximately $0.5 \mathrm{~mm}$ caudal to $3.5 \mathrm{~mm}$ caudal from bregma). 


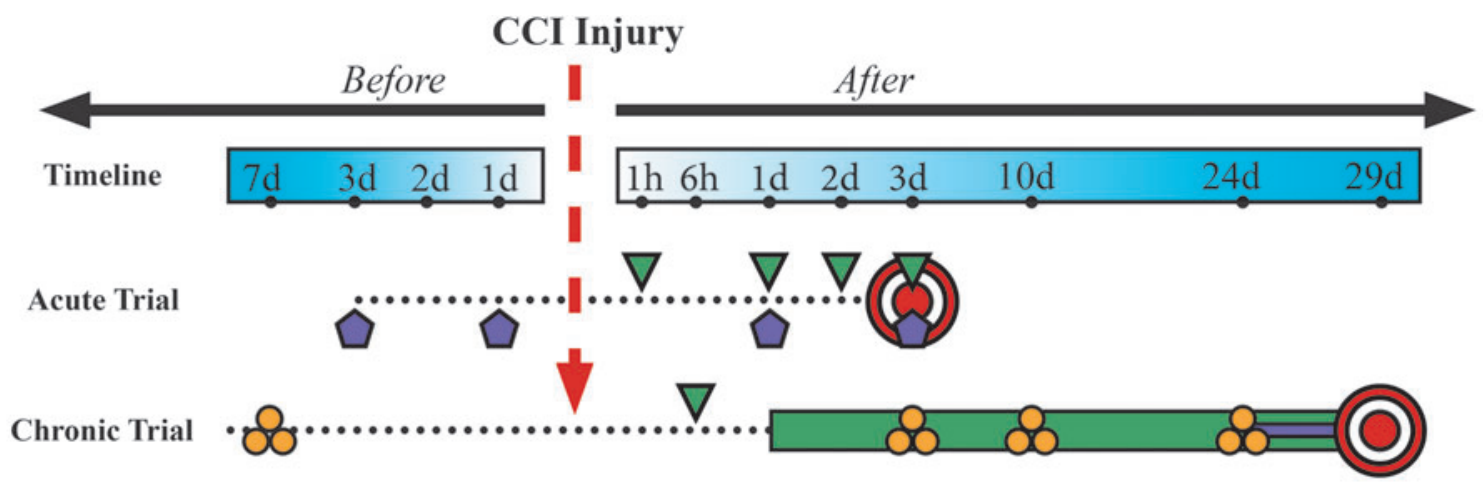

Legend
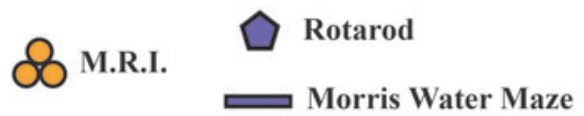

$\nabla$ Single SQ Injection

Continuous SQ Infusion

Histology/Immunohistochemistry

FIG. 1. Experimental design. Different cohorts of mice were subjected to controlled cortical injury (CCI) injury and sacrificed at either 3 or 29 days post-injury (dpi) for immunohistochemical and histological analysis of brain sections. Motor coordination after injury was assessed by rotarod in the acute trial, and cognitive function by Morris Water Maze in the final week of the chronic trial. Magnetic resonance imaging was performed 7 days before injury and at 3, 10, and $24 \mathrm{dpi}$ in the chronic trial.

\section{Cresyl violet staining and histological lesion volume measurements}

Cresyl violet ( $0.1 \%$, Sigma-Aldrich) was dissolved in deionized water and filtered. Every 12th brain section was mounted on gelatin-coated slides. Sections were sequentially hydrated for $2 \mathrm{~min}$ each with 100, 95, 70, and 50\% ethanol, and then stained for $10 \mathrm{~min}$ with cresyl violet solution. Subsequently, sections were sequentially dehydrated for 2 min with 50, 70, 95, and 100\% ethanol, and then cleared in xylene for another $2 \mathrm{~min}$. Slides were covered with Cytoseal 60 (Richard-Allan Scientific, Ft. Washington, PA; Cat. \# 18007) and protected with a cover-slip.

Lesion area was assessed on seven to 15 sections $(20 \mu \mathrm{m})$ per brain spaced every $240 \mu \mathrm{m}$ (every 12th section) from the rostral to caudal edge of the visible lesion. Lesion volume was calculated by multiplying the total distance between sections by the average cross-sectional area of the lesion. Lesion was defined as any asymmetrical morphology in the ipsilateral hemisphere with respect to the contralateral. If a brain section had an uneven coronal cut and the lesion spanned into the lateral ventricle, the section was excluded. If $50 \%$ or more sections of any mouse was excluded, no lesion area data was included from that mouse.

\section{Immunohistochemical analysis}

Sections were washed three times in phosphate-buffered saline with $0.1 \%$ Triton $^{\mathrm{TM}} \mathrm{X}-100$ (PBST) for 5 min each, and blocked with $10 \%$ normal goat serum (NGS) in PBST for $1 \mathrm{~h}$. The following primary antibodies were incubated at $4^{\circ} \mathrm{C}$ overnight in PBST/5\% NGS: anti-glial fibrillary acidic protein (GFAP), chicken polyclonal (1:1000; Abcam; Ab4647); anti-Iba1, mouse monoclonal (1:1000; Wako; 019-19741); anti-NeuN, mouse monoclonal (1:1000; Millipore; NG1876252); or anti-CD31, rat monoclonal (1:300; BD Biosciences; 550274). Sections were washed three times in PBST and incubated with either Alexa Fluor 568-conjugated (red), Alexa Fluor $^{\circledR}$ 488-conjugated (green), or Alexa Fluor 647-conjugated (far-red) IgG secondary antibody (1:1000, Invitrogen) overnight at $4^{\circ} \mathrm{C}$. Sections were then rinsed with PBST and deionized water, mounted on gelatin coated slides, covered with ProLong Gold antifade reagent with $4^{\prime}, 6$-diamidino-2-phenylindole (Invitrogen), and protected with cover-slips.

\section{Immunohistochemical quantification}

Brightfield and fluorescent images were acquired with the $\times 10$ and $\times 20$ objective, respectively, on the ZEISS Axioscan.Z1 utilizing ZEN microscope software (Zeiss). Fluorescent images also were acquired with the $\times 20$ objective on an Olympus BX61 with attached qImaging Retiga EXi Aqua CCD camera, and iVision software (BioVision Technologies).

Quantitative image analysis was performed on at least four lesion-including sections per mouse, from between $2.50 \mathrm{~mm}$ caudal and $1.50 \mathrm{~mm}$ caudal from bregma. For each neuroanatomical region in question, immunoreactivity or cell count was assessed in a total of five randomly selected viewing fields per region, per section. Iba1+ microglia counts were acquired using an intensitythresholded and size-gated automated counting method in ImageJ and were divided by the total area in the image field $\left(\mathrm{mm}^{2}\right)$. Similar methods were used for NeuN+ neuron counts and CD31+ capillary density. GFAP immunofluorescent intensity was quantified by dividing the number of post-threshold pixels with the area of the image field. The investigator was blinded to the treatment throughout the quantification process.

\section{$M R I$}

MRI was performed on a 7 Tesla small animal (20-cm horizontal bore) Bruker BioSpec scanner (20-cm horizontal bore) with 120$\mathrm{mm}$ diameter, $670 \mathrm{mT} / \mathrm{m}$ gradient coils and four-channel phased array surface receive magnetic resonance radiofrequency $(\mathrm{RF})$ coil with 86-mm inner diameter volume RF transmit coil (Bruker Biospin, Inc., Billerica, MA). Mice were anesthetized with isoflurane (3\% induction, $2 \%$ maintenance) and placed on a specialized small animal holder atop a precision controlled-heating pad. Proton density weighted imaging, T2-weighted imaging (T2W), and T2-maping (T2map) was performed utilizing multi-echo twodimensional Rapid Acquisition with Relaxation Enhancement (2DRARE) with the following parameters: repetition time, $4500 \mathrm{msec}$; echo time, 10, 30, 50, 70, 90, and $110 \mathrm{msec}$; echo train length, 2; number of averages, 4; field of view, $13.8 \times 11.2 \mathrm{~mm}^{2}$; in-plane resolution, $150 \times 150 \mu \mathrm{m}^{2}$; 26 coronal slices, slice thickness, $600 \mu \mathrm{m}$. Each mouse underwent MRI 7 days prior to injury, and 3, 10, and 24 dpi. Respiration, heart rate, $\mathrm{SpO}_{2}$, and temperature were recorded every 10 min during imaging. 


\section{MRI lesion volume calculation}

Lesion was defined as any asymmetrical signal or morphology in the ipsilateral hemisphere with respect to the contralateral. Structural or signal abnormalities that appeared unrelated to injury were compared with baseline images. The investigator was blinded to the treatment throughout the quantification process.

\section{Statistical analysis}

All data in this study are expressed as mean \pm standard error of the mean (SEM). A $p<0.05$ was considered statistically significant. All experiments that simultaneously compared vehicle with Ang(1-7) treatment and sham to injury were evaluated using a two-way analysis of variance (ANOVA) with Tukey's multiple comparisons corrections. Experiments that compared treatment start times were evaluated with a one-way ANOVA with Tukey's multiple comparisons testing. Experiments that simultaneously compared vehicle to Ang-(1-7) over time were evaluated using a repeated-measure two-away ANOVA with Sidak's multiple comparison test. Experiments that solely compared vehicle with Ang-(1-7) were evaluated using an unpaired, parametric, two-tailed t-test. All previously mentioned statistics were analyzed with GraphPad Prism 7 software (GraphPad Software, CA). To assess spatiotemporal learning during the MWM, latency to platform was compared with time and treatment by three-way ANOVA in Statistical Package for the Social Sciences (SPSS; IBM, NY).

\section{Results}

\section{Ang-(1-7) treatment reduces lesion volume after $\mathrm{CCl}$}

To determine if subcutaneous administration of Ang-(1-7) was neuroprotective after CCI, we treated mice with $1 \mathrm{mg} / \mathrm{kg} /$ day of Ang-(1-7) or vehicle, starting $1 \mathrm{~h}$ after injury, and sacrificed the mice at 3 dpi (Fig. 2). We based this dose on other studies showing effects of subcutaneous administration of Ang-(1-7) in mice between 0.5 and $1.2 \mathrm{mg} / \mathrm{kg} /$ day. $^{24,25,32}$ Quantification of the lesion size on cresyl violet-stained brain sections showed that Ang-(1-7) treatment significantly reduced lesion volume in comparison to that of vehicle-treated injured mice (Fig. 2A, 2B). To determine whether this neuroprotective effect was detectable over a longer duration of treatment, we repeated the experiment, starting treatment at $6 \mathrm{hpi}$ and maintaining continuous Ang-(1-7) infusion ( $1 \mathrm{mg} / \mathrm{kg} / \mathrm{day})$ until sacrifice at $29 \mathrm{dpi}$ (Fig. 2). Quantification of the lesion volume in brains taken from these mice showed a similar protective effect, with Ang-(1-7) treatment leading to a smaller lesion volume after 29 days of treatment (Fig. 2A, 2C).

To assess whether lesion size at time of sacrifice accurately represented changes of lesion volume in vivo, we performed CCI on a different cohort of mice, and treated them with Ang-(1-7) or vehicle, for 29 days, starting $6 \mathrm{~h}$ after CCI. We utilized magnetic resonance imaging (MRI) to visualize changes in the lesion size with time by measuring the lesion at 3,10 and 24 dpi. Using T2weighted MRI to calculate lesion volume (Fig. 2D), Ang-(1-7) treatment led to reduction in lesion volume at 3,10, and $24 \mathrm{dpi}$ (Fig. 2E). Thus, Ang-(1-7) treatment results in a smaller lesion after CCI injury.

\section{Ang-(1-7) treatment reduces acute microgliosis following $\mathrm{CCl}$}

To determine whether Ang-(1-7) administration altered the activation or survival of glial cells after CCI, we assessed staining for glial-specific markers in brain sections taken from mice treated with Ang-(1-7) or vehicle and sacrificed at 3 dpi. We examined staining in the perilesional cortex, ipsilateral thalamus (centered around the anterior thalamic nuclei), and contralateral hippocampus (centered around CA3). We assessed the contralateral hippocampus, as the ipsilateral hippocampus was disrupted by injury to variable amounts, which made assessment of staining within it extremely difficult. Additionally, significant changes have been noted in the contralateral hippocampus after CCI. ${ }^{33}$ However, we anticipated less robust alterations in the contralateral hippocampus compared to the ipsilateral brain regions examined due to its distance from the impact. We found a robust increase of Iba1+ microglia as well as GFAP+ astrocytes in each brain region after CCI (Fig. 3). We found that Ang-(1-7) treatment significantly reduced the number of Iba1+ microglia in each brain region examined, but did not reduce the level of GFAP + astrocytic staining in any of these brain regions. Microglia in vehicle-treated mice after CCI displayed an activated phenotype with a dramatic increase in soma size and overall amoeboid morphology at $3 \mathrm{dpi}$ (Fig. 3C, 3K, 3S, 3AE). Ang-(1-7) treatment significantly reduced microglia soma size and promoted a spindle morphology, indicating an overall reduction in microglial activation (Fig. 3D, 3L, 3T, 3AE).

\section{Acute capillary and neuronal changes following $\mathrm{CCl}$}

Traumatic insults to the CNS can adversely affect neurons and capillary networks formed by cerebrovascular endothelial cells. We assessed the effect of Ang-(1-7) treatment on CD31+ endothelial cells and NeuN+ neurons in brains taken from mice sacrificed at 3 dpi (Fig. 4). Immunohistochemical assessment demonstrated a decrease of both capillary and neuronal density in the perilesional cortex and ipsilateral thalamus following CCI (Fig. 4A-P, 4Y-AB). However, neither CD31+ or NeuN+ staining was altered by Ang(1-7) treatment at 3 dpi (Fig. 4D, 4H, 4L, 4P, 4Y-AB). We did not detect any injury-induced change in capillary or neuronal density in the contralateral hippocampus (Fig. 4Q-X, 4AC, 4AD).

\section{Ang-(1-7) reduces astrogliosis and microgliosis one month after $\mathrm{CCl}$}

As Ang-(1-7) treatment altered the lesion volume over several different time-points, we wanted to determine the effects that longer Ang-(1-7) treatment had on glial activation beyond $3 \mathrm{dpi}$. We therefore determined whether continuous treatment with Ang(1-7) for 29 days altered the number of Iba1+ microglia, or the amount of GFAP+ astrocytic staining, in brains of mice (Fig. 5). Robust astrogliosis was present in the perilesional cortex, ipsilateral thalamus, and contralateral hippocampus 29 days after CCI (Fig. 5G, 5O, 5W, 5Z, 5AB, 5AD). Ang-(1-7) treatment resulted in significant reduction of GFAP+ astrocytic staining in all three brain regions at $29 \mathrm{dpi}$ (Fig. 5H, 5P, 5X, 5Z, 5AB, 5AD). In the cortex, the glial scar is visible at the lesion edge, and is noticeably thinner after Ang-(1-7) treatment (Fig. 5G, 5H). The number of Iba1+ cells 29 days after $\mathrm{CCI}$ in the perilesional cortex and ipsilateral thalamus was greater than in sham mice (Fig. 5A-D, 5Z, 5I-L, 5AA). However, there was no difference between injured and sham mice in the number of Iba1+ microglia in the contralateral hippocampus at this time-point (Fig. 5Q-T, 5AC). Microglia in the contralateral hippocampus had also reverted to the resting morphology, in contrast to the ameboid shape of microglia in the ipsilateral thalamus and perilesional cortex (Fig. 5C, 5K, 5S). Ang-(1-7) treatment reduced the number of Iba1+ microglia in the ipsilateral thalamus, but did not alter Iba1+ cells in the perilesional cortex (Fig. 5I-L, 5AA; 5A-D, 5Z). 

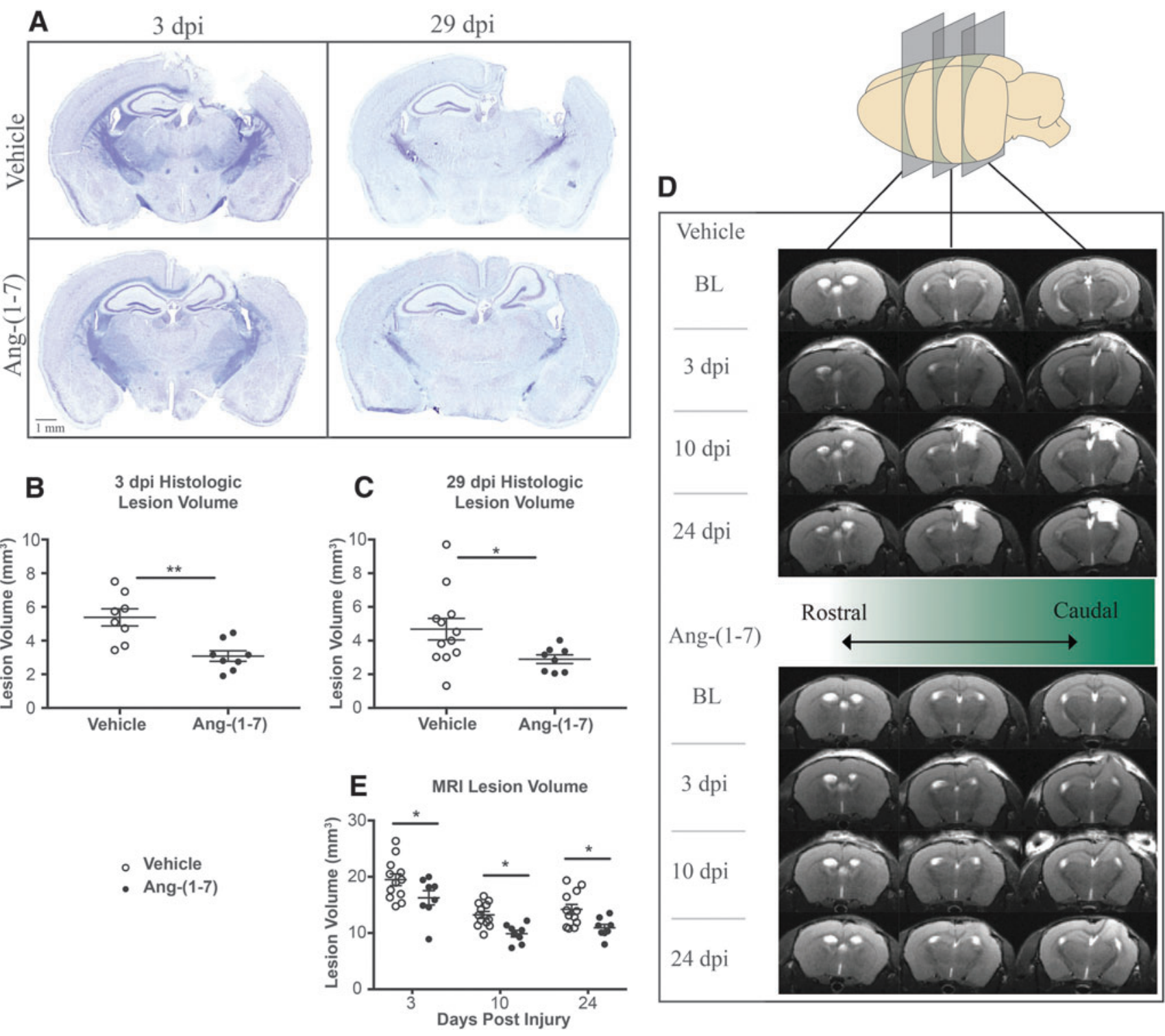

FIG. 2. Lesion volume assessed by histology and magnetic resonance imaging (MRI) at different time-points after controlled cortical injury (CCI). (A) Representative cresyl violet-stained brain sections from CCI injured mice treated with either vehicle or angiotensin(1-7) [Ang-(1-7); $1 \mathrm{mg} / \mathrm{kg}$ ] for either 3 or 29 days. Graph of lesion volume in brain sections sacrificed at (B) 3 or (C) 29 days post-injury (dpi); $n=8-13$. Data are mean \pm standard error of the mean (SEM); $* *<0.01$, * $p<0.05$. (D and E) Mice brains were assessed using T2weighted MRI before injury (baseline [BL]), and at 3, 10, and 24 dpi for cohorts treated with either vehicle or Ang-(1-7) after CCI. (D) Representative MRI from different mice showing the variation in lesion size (hyperintense regions) from rostral to caudal over time and with treatment. (E) Graph of lesion volume at 3, 10 and 24 dpi; $n=8-12$, mean \pm SEM, $* p<0.05$.

\section{Ang-(1-7) treatment preserves capillary and neuronal density 1 month after $\mathrm{CCl}$}

To determine the effect of longer treatment with Ang-(1-7) on capillary and neuronal density after CCI, we examined brains taken from mice after 29 days of treatment. Brain sections from Ang-(17)-treated injured mice had a greater density of neurons in the ipsilateral thalamus than sections from vehicle-treated injured mice (Fig. 6O, 6P, 6AB). However, Ang-(1-7) treatment did not alter the injury-induced reduction in neuronal density in the perilesional cortex (Fig. 6G, 6H, 6Z). The contralateral hippocampus did not exhibit any change in neuron density with injury (Fig. 6W, 6X, 6AD). The effect of Ang-(1-7) treatment on CD31+ capillary density mirrored that of neuronal density. Prolonged Ang-(1-7) treatment led to an increase in the injury-reduced density of CD31+ capillaries in the ipsilateral thalamus (Fig. 6K, 6L, 6AA). Ang-(17) treatment did not alter the injury-induced reduction in capillary density in the perilesional cortex (Fig. 6C, 6D, 6Y), and there was no injury effect on the density of $\mathrm{CD} 31+$ capillaries in the contralateral hippocampus (Fig. 6S, 6T, 6AC).

\section{Ang-(1-7) benefits functional recovery following $\mathrm{CCl}$}

To determine if Ang-(1-7) treatment altered functional recovery from injury, we assessed mice for motor coordination deficits at various time-points after CCI. We assessed motor coordination by measuring latency to fall from a rotating rod at baseline, $1 \mathrm{dpi}$, and 3 dpi. At both 1 and 3 dpi, vehicle-treated injured mice developed 


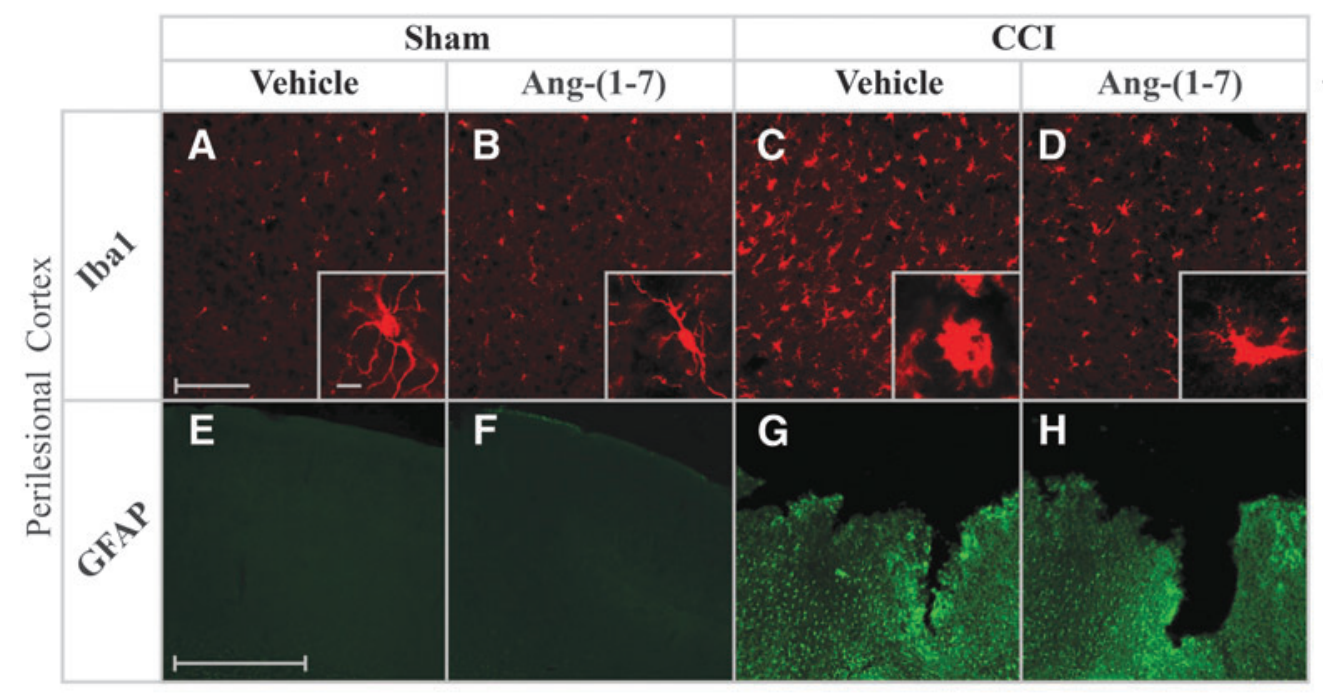

$\square$ Vehicle Ang-(1-7)
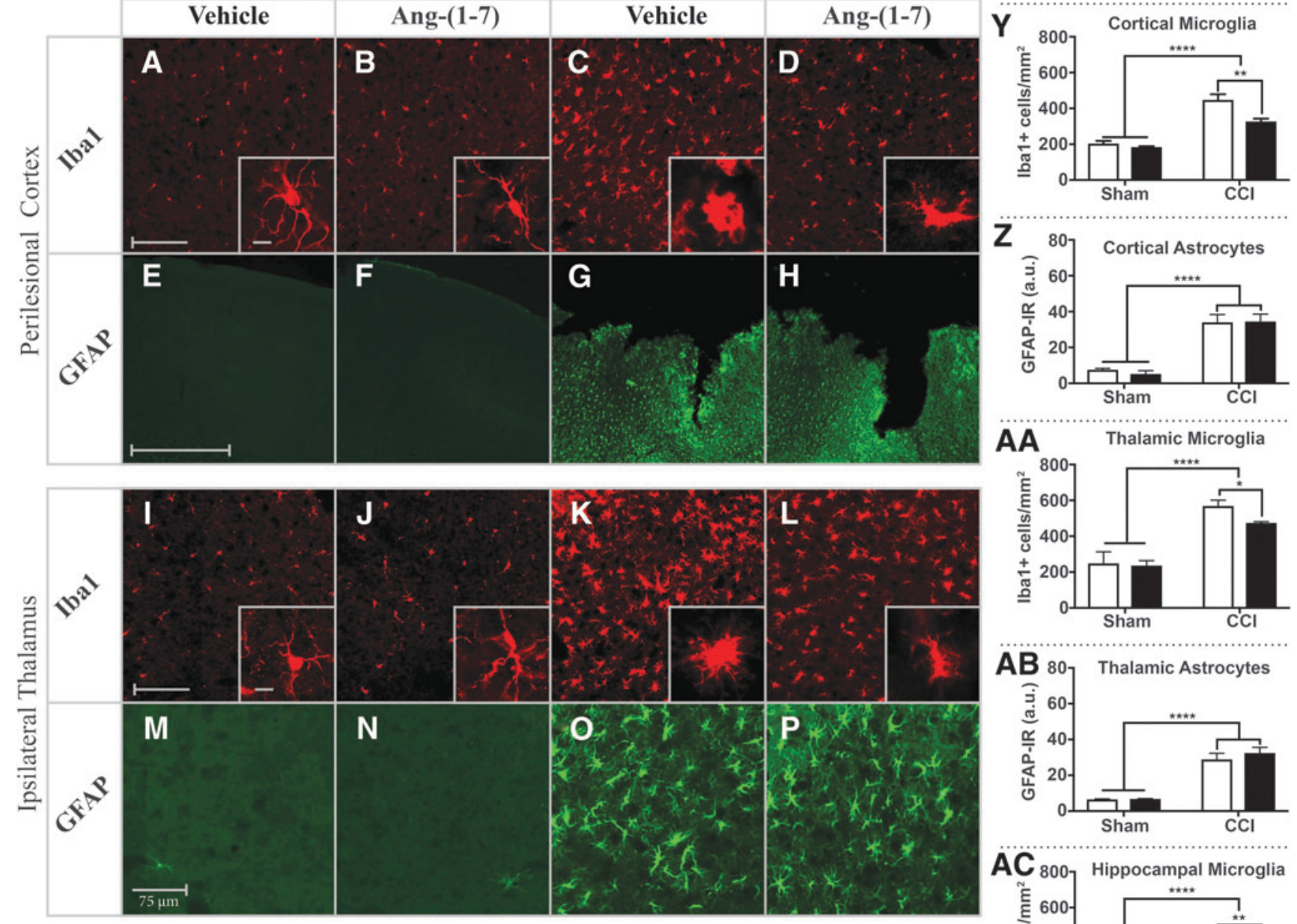

$\mathbf{A C}_{800}$ Hippocampal Microglia
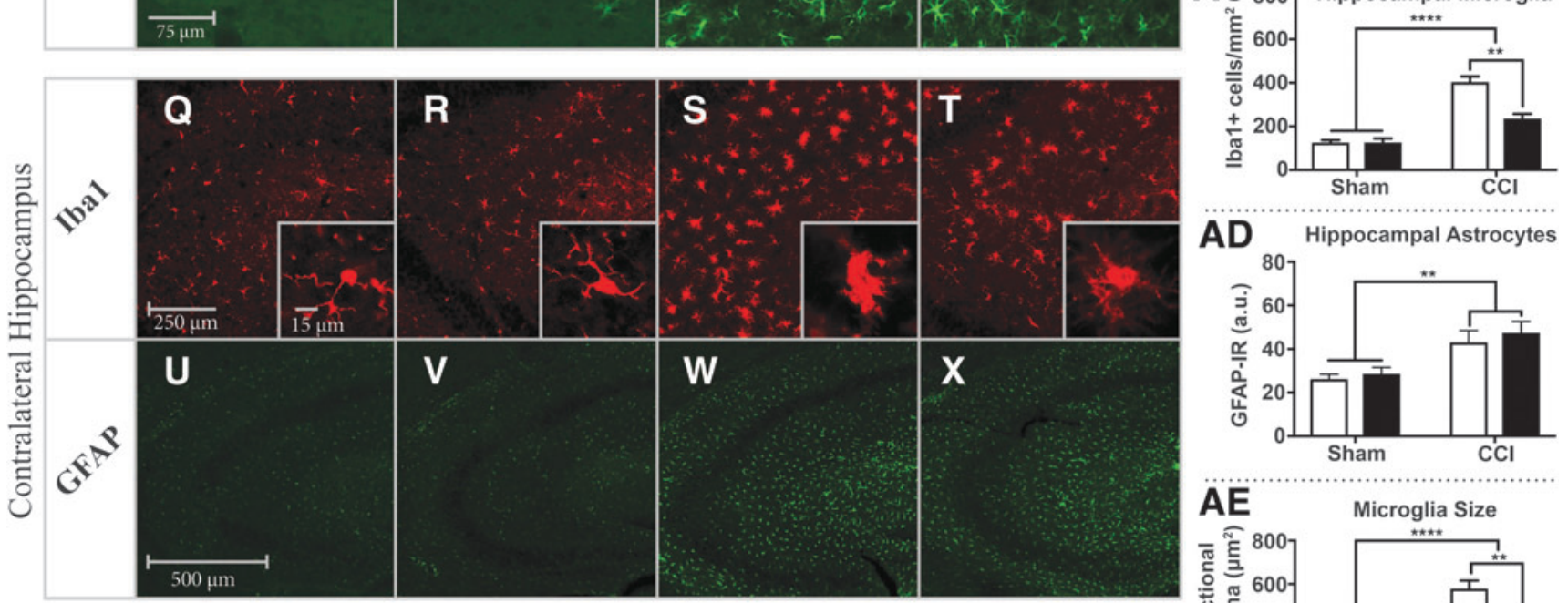

AD Hippocampal Astrocytes
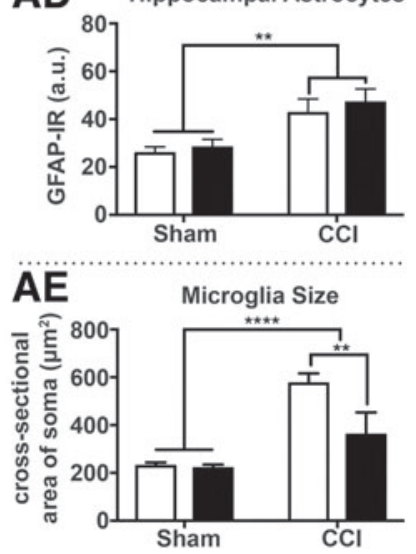

FIG. 3. Acute gliosis at 3 days post-injury (dpi). (A-X) Representative immunohistochemistry of brain sections from controlled cortical injury (CCI) injured or sham mice treated with vehicle or angiotensin-(1-7) [Ang-(1-7)] sacrificed at 3 dpi. Microglial reactivity was determined in the perilesional cortex (A-D, Y), ipsilateral thalamus (I-L, AA), and contralateral hippocampus (Q-T, AC), by counting Iba1+ cells $/ \mathrm{mm}^{3}$. Microglia soma size was assessed in the perilesional cortex (AE). Insets show morphology of individual microglia in each brain region following indicated treatment. Reactive astrocytes were assessed by quantifying glial fibrillary acidic protein (GFAP) immunoreactivity (IR) in the perilesional cortex (E-H, Z), ipsilateral thalamus (M-P, AB), and contralateral hippocampus (U-X, AD); $n=3-5$ mice/group, mean \pm standard error of the mean; $* p<0.05, * * p<0.01, * * * p<0.001, * * * *<0.0001$. a.u., arbitrary unit. 

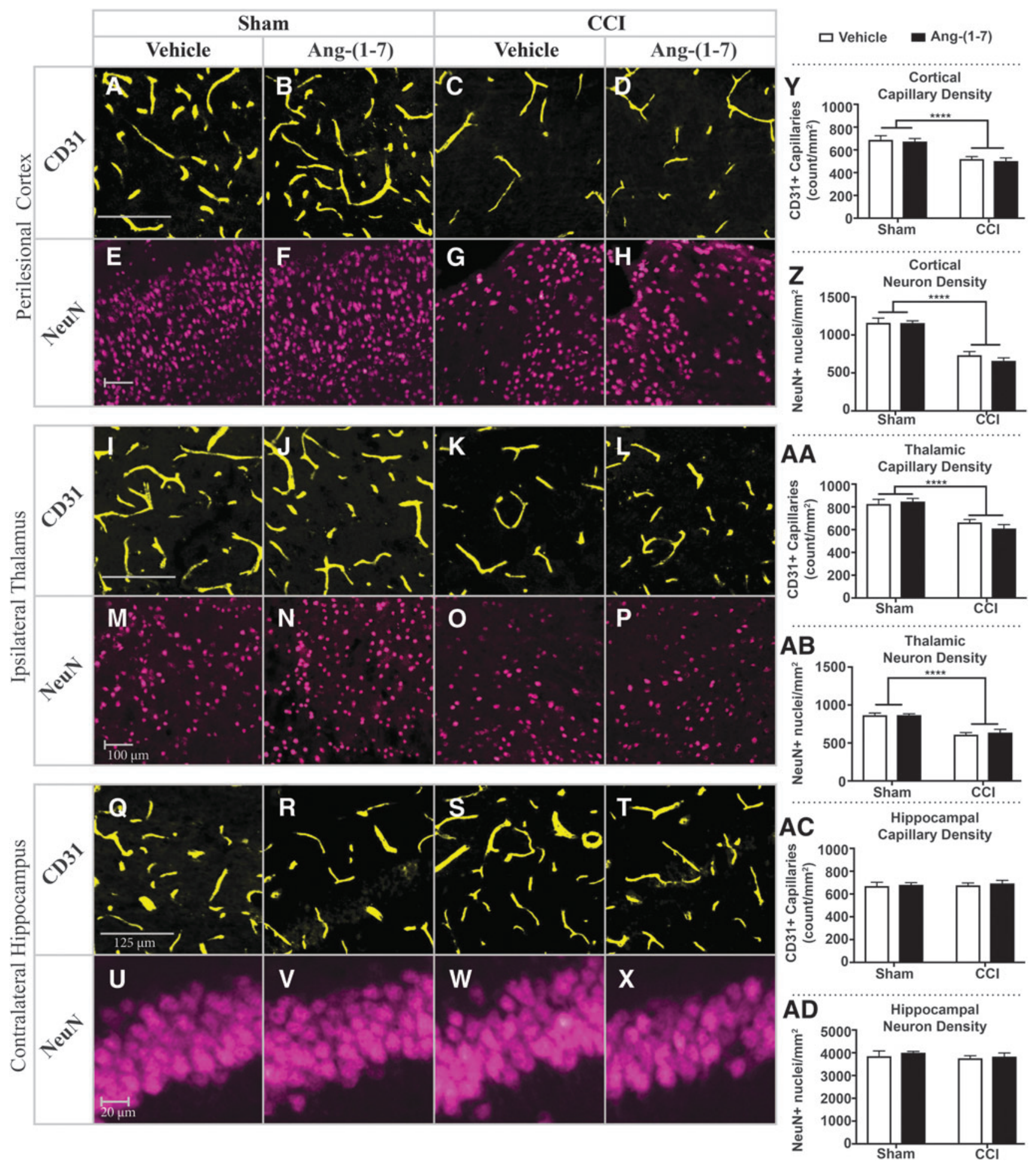

FIG. 4. Effect of angiotensin-(1-7) [Ang-(1-7)] treatment on neurons and microvasculature in different brain regions at 3 days postinjury (dpi). (A-X) Representative immunohistochemistry of sections from different brain regions taken from controlled cortical injury (CCI) injured or sham mice treated with vehicle or Ang-(1-7) sacrificed at 3 dpi. Capillary density was determined in the perilesional cortex (A-D, Y), ipsilateral thalamus (I-L, AA), and contralateral hippocampus (Q-T, AC) by counting CD $31+$ structures/mm ${ }^{3}$. Density of neurons was assessed by counting $\mathrm{NeuN}+$ nuclei $/ \mathrm{mm}^{3}$ in the perilesional cortex $(\mathrm{E}-\mathrm{H}, \mathbf{Z})$, ipsilateral thalamus $(\mathbf{M}-\mathrm{P}$, $\mathbf{A B})$, and contralateral hippocampus (U-X, AD); $n=3-5$ mice/group, mean \pm SEM; $* * * p<0.001, * * * * p<0.0001$. 


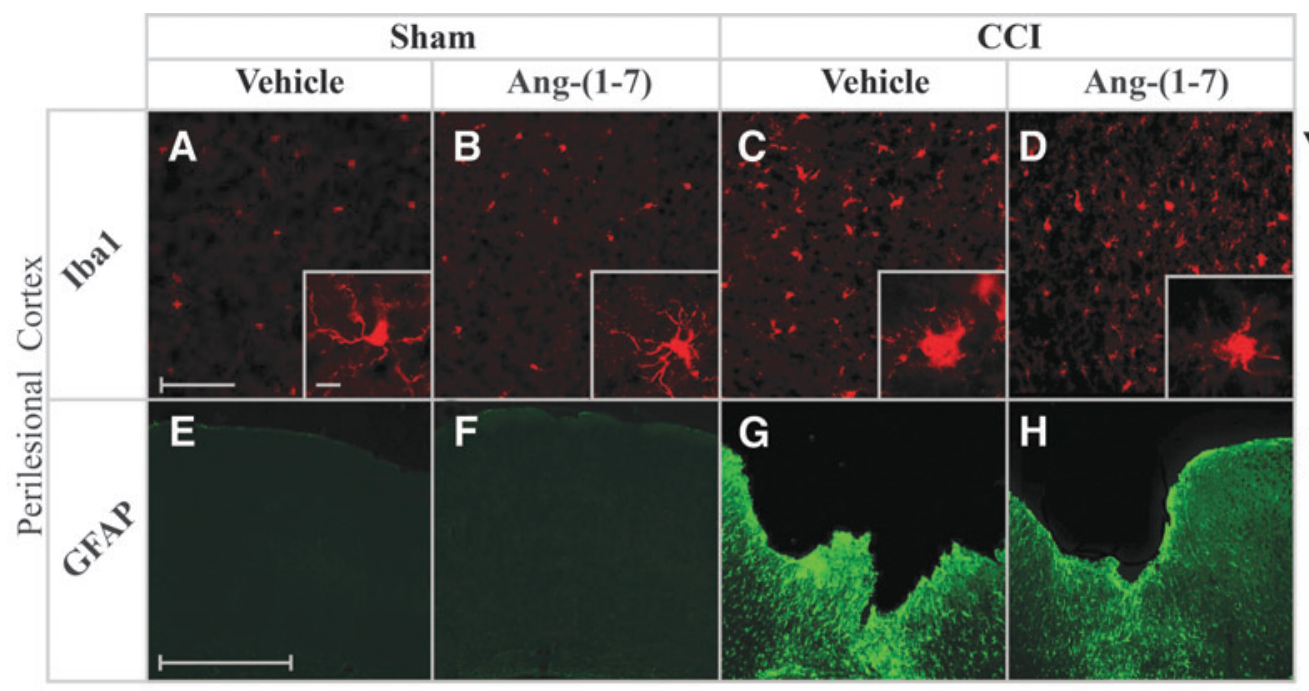

므icle Ang-(1-7)

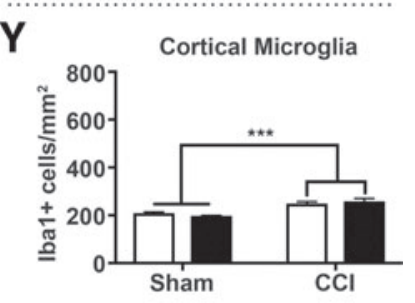

Z Cortical Astrocytes
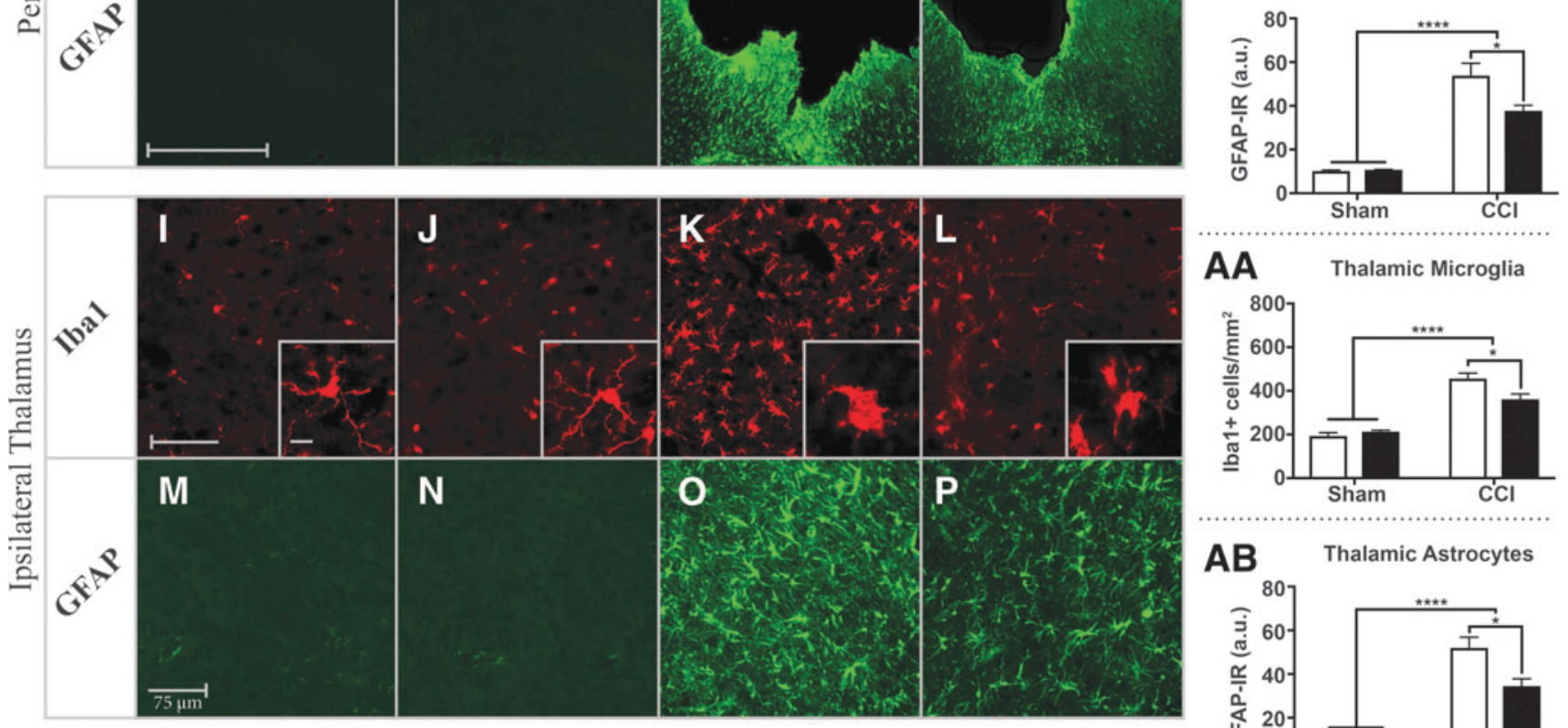

AA Thalamic Microglia

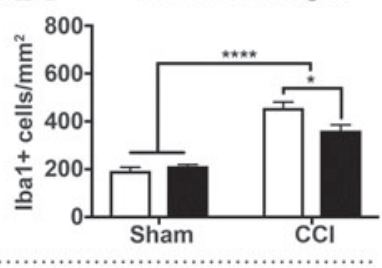

AB Thalamic Astrocytes
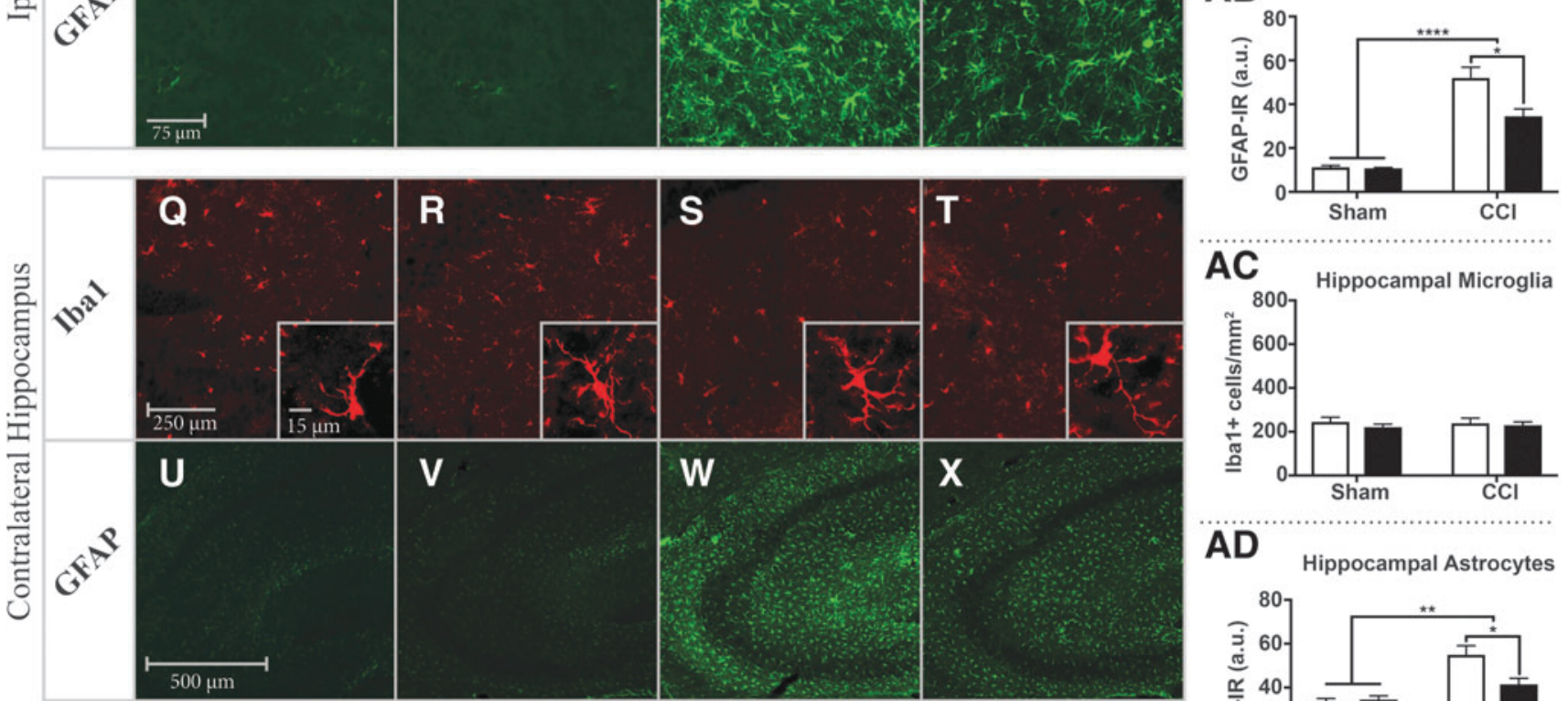

AD

Hippocampal Astrocytes

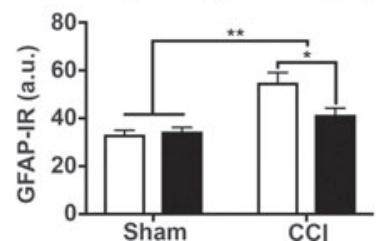

FIG. 5. Glial reactivity at 29 days post-injury (dpi). (A-X) Representative immunohistochemistry of brain sections from controlled cortical injury (CCI) injured or sham mice treated with vehicle or angiotensin-(1-7) [Ang-(1-7)] sacrificed at $29 \mathrm{dpi}$. Microglial reactivity was determined in the perilesional cortex (A-D, Y), ipsilateral thalamus (I-L, AA), and contralateral hippocampus (Q-T, AC), by counting Iba1+ cells/ $\mathrm{mm}^{3}$. Insets show morphology of individual microglia in each brain region following indicated treatment. Reactive astrocytes were assessed by quantifying glial fibrillary acidic protein (GFAP) immunoreactivity (IR) in the perilesional cortex $(\mathrm{E}-\mathrm{H}, \mathbf{Z})$, ipsilateral thalamus (M-P, AB), and contralateral hippocampus (U-X, AD); $n=3-5$ mice/group, mean \pm standard error of the mean; $* p<0.05, * * p<0.01, * * * p<0.001, * * * * p<0.0001$. a.u., arbitrary unit. 

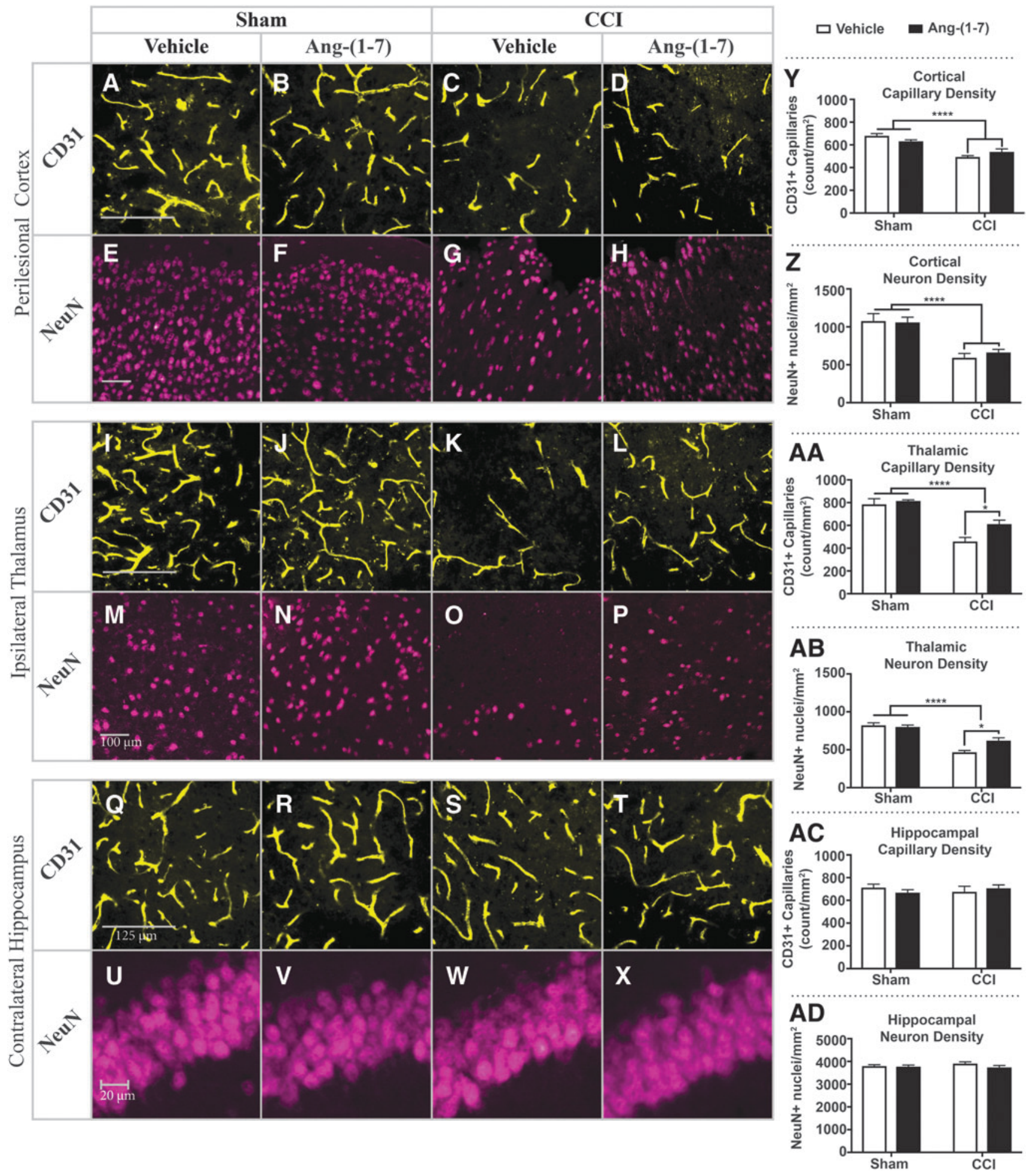

FIG. 6. Effect of angiotensin-(1-7) [Ang-(1-7)] treatment on neurons and microvasculature in different brain regions at 29 days postinjury (dpi). (A-X) Representative immunohistochemistry of sections from different brain regions taken from controlled cortical injury (CCI) injured or sham mice treated with vehicle or Ang-(1-7) sacrificed at 29 dpi. Capillary density was determined in the perilesional cortex (A-D, Y), ipsilateral thalamus (I-L, AA), and contralateral hippocampus (Q-T, AC) by counting CD $31+$ structures $/ \mathrm{mm}^{3}$. Density of neurons was assessed by counting $\mathrm{NeuN}+$ nuclei $/ \mathrm{mm}^{3}$ in the peri-lesional cortex $(\mathrm{E}-\mathrm{H}, \mathbf{Z})$, ipsilateral thalamus $(\mathrm{M}-\mathrm{P}, \mathbf{A B})$, and contralateral hippocampus (U-X, AD); $n=3-5$ mice/group, mean \pm standard error of the mean; * $p<0.05, * * * *<0.0001$. 
significant motor coordination deficits, falling off the rotating rod earlier than uninjured mice (Fig. 7A). The latency to fall of Ang-(17)-treated injured mice was not significantly different than either vehicle-treated sham mice, or vehicle-treated injured mice, indicating an intermediate motor phenotype at both 1 and 3 dpi (Fig. 7A). Ang(1-7) treatment had no effect on sham-treated mice.

To determine whether Ang-(1-7) altered CCI-induced spatiotemporal learning and memory deficits, we assessed performance of the mice in the Morris Water Maze (MWM) from 24 to 28 dpi. On training days 3, 4 and 5, (26-28 dpi), the vehicle-treated injured mice took longer to find the submerged platform than either sham mice, or Ang-(1-7)-treated injured mice, indicating that Ang-(1-7) treatment was beneficial during the training period (Fig. 7B). In the probe trial performed at $28 \mathrm{dpi}$, injured mice spent significantly less time in the quadrant where they had been trained to find the platform than did uninjured mice (Fig. 7C). Ang-(1-7)-treated injured
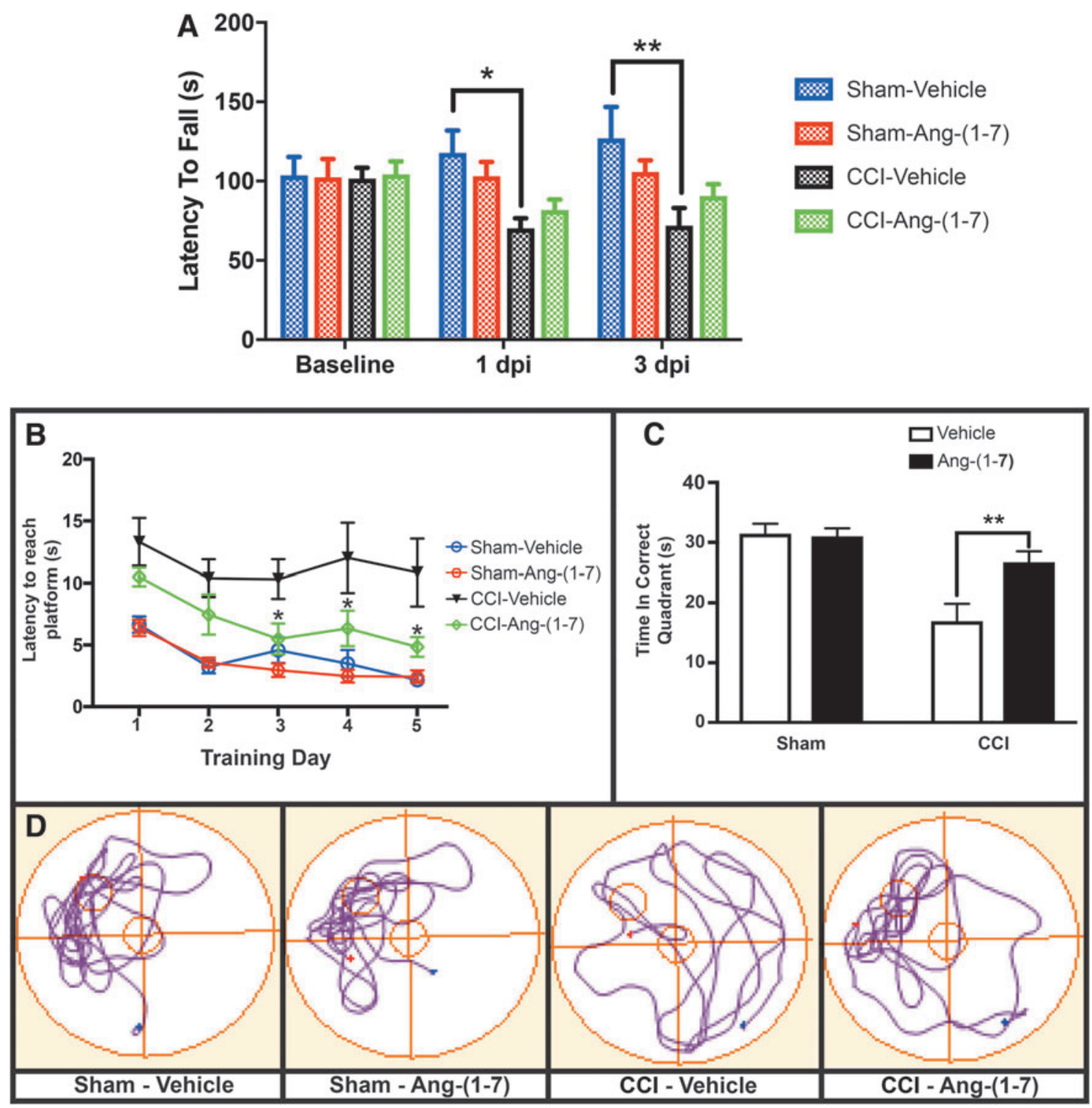

FIG. 7. The effect of angiotensin-(1-7) [Ang-(1-7)] treatment on motor performance and spatial memory after controlled cortical injury (CCI). (A) Recovery of motor coordination after CCI in mice treated with either Ang-(1-7) or vehicle was assessed by performance on the rotarod from 1 to 3 days post-injury (dpi). Mean \pm standard error of the mean (SEM); $n=8-9$. $* p<0.05, * * p<0.01$. (B) Rates of spatial learning were assessed using the Morris Water Maze from 24 to 28 dpi (Days 1-5). Average time taken to reach the platform each day was recorded. ${ }^{*} p<0.05$ comparing CCI-Vehicle with CCI-Ang-(1-7). (C) On the fifth day (28 dpi), mice were assessed for spatial memory retention during a $60 \mathrm{sec}$ probe trial $1 \mathrm{~h}$ after the final training; $n=18-19$ mice/group, mean \pm SEM, $*^{*} p<0.01$. (D) Representative track plots of swimming patterns during the probe trial. 
mice spent significantly more time in the correct quadrant than did vehicle-treated injured mice (Fig. 7C). Thus, Ang-(1-7) treatment not only prevented significant motor coordination deficits from developing early after CCI, it significantly improved spatiotemporal learning and memory up to 1 month after injury.

\section{Extending the therapeutic time window of treatment}

As we have shown that Ang-(1-7) treatment starting 6h postinjury (hpi) reduced lesion volume, we wanted to determine whether we could extend the therapeutic time window to initiate Ang(1-7) treatment. We therefore injured mice by CCI, and initiated Ang-(1-7) treatment by a single subcutaneous (S.Q.) injection $(1 \mathrm{mg} / \mathrm{kg})$ at either 6,24 , or $72 \mathrm{hpi}$. Twenty-four hours after the initial injection, we implanted a S.Q. micro-osmotic pump to dispense Ang-(1-7) by continuous infusion until sacrifice at 29 dpi. As in our previous experiments, starting subcutaneous administration of Ang-(1-7) $6 \mathrm{~h}$ after CCI significantly reduced lesion volume when assessed by histology at 29 dpi (Fig. 8). Starting administration of Ang-(1-7) $72 \mathrm{~h}$ after injury did not reduce lesion volume relative to vehicle-treated injured mice. However, initiating Ang(1-7) treatment at $24 \mathrm{~h}$ after injury resulted in a lesion size that was not significantly different from that found after initiating treatment at $6 \mathrm{~h}$ or at $72 \mathrm{~h}$, suggesting an intermediate effect (Fig. 8).

\section{Neuroprotection by Ang-(1-7) following CCl is MasR mediated}

The major receptor through which Ang-(1-7) signals is the MasR. ${ }^{19}$ However, other receptors also may mediate Ang-(1-7) signaling. ${ }^{34}$ We therefore sought to determine whether Ang-(1-7) efficacy in reducing lesion volume was MasR-mediated, through the use of the MasR antagonist, A779. We initiated continuous S.Q. infusion of MasR antagonist (A779) through a micro-osmotic pump implanted 2 days prior to injury and continued treatment until the time of sacrifice. Mice were injured by CCI as before, and Ang-(17) treatment was initiated $6 \mathrm{~h}$ after injury and continued by daily S.Q. injection until sacrifice at $3 \mathrm{dpi}$. As expected, determination of lesion volume on cresyl violet-stained sections showed that brains from Ang-(1-7)-treated mice had a significantly smaller lesion size compared to that in brain sections from vehicle-treated mice (Fig. 9). However, in mice pre-treated with A779, the protective effect of Ang-(1-7) treatment was not detectable. The lesion volume in brains taken from mice treated with both Ang-(1-7) and A779 was significantly larger than that of injured mice treated with Ang-(1-7) alone (Fig. 9). Further, A779 treatment alone did not alter lesion volume after CCI (Fig. 9). Thus, the ability of Ang-(1-7) to reduce lesion volume is dependent, at least in part, on MasR signaling.

A
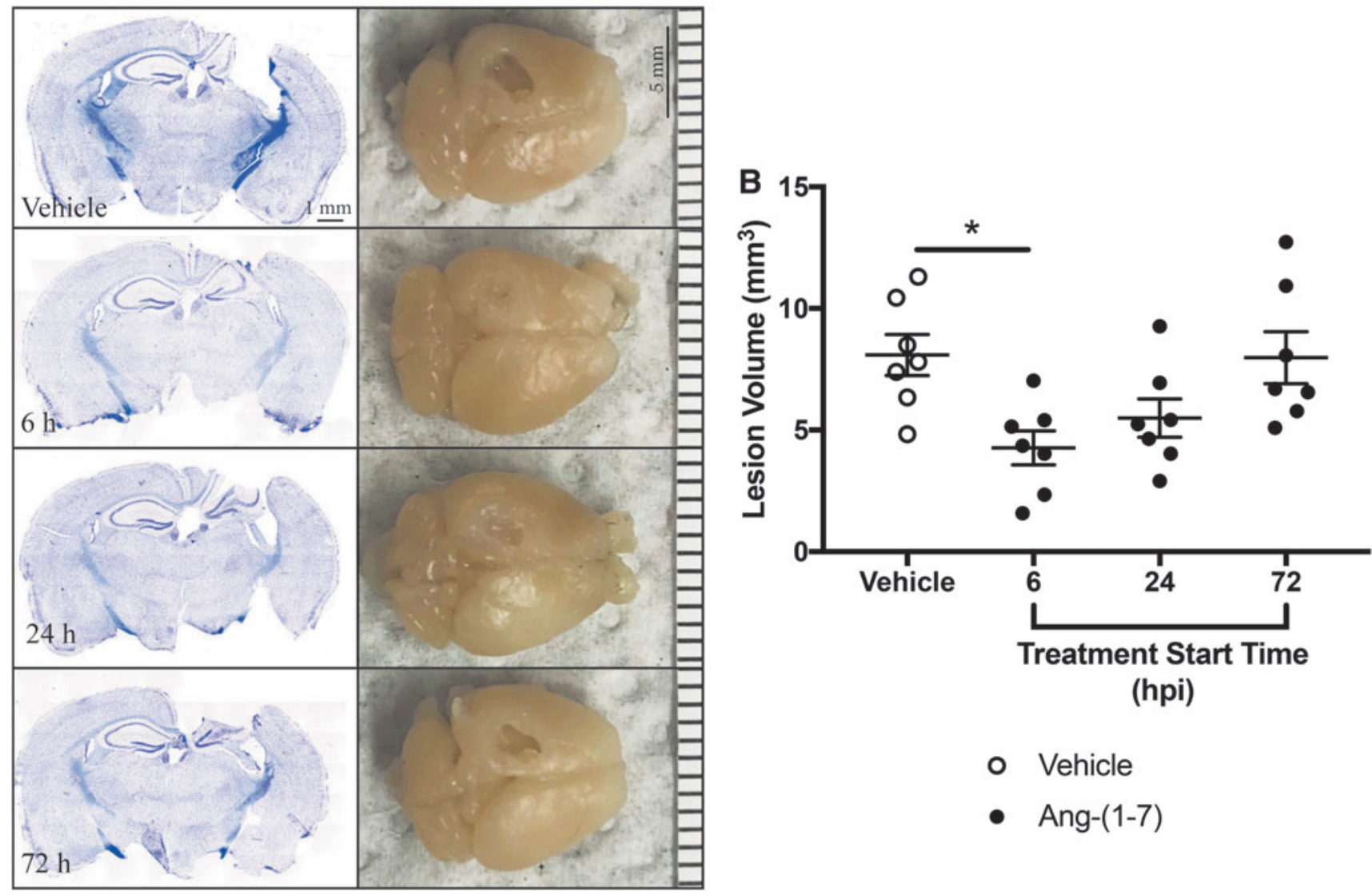

- Vehicle

- Ang-(1-7)

FIG. 8. Determination of the therapeutic time window for Ang-(1-7) treatment after controlled cortical injury (CCI). Angiotensin-(1-7) [Ang(1-7)] treatment was initiated by subcutaneous injection starting at 6,24 , or $72 \mathrm{~h}$ post-injury after CCI. One day after the initial injection, a microosmotic pump was implanted to allow continuous Ang-(1-7) treatment ( $1 \mathrm{mg} / \mathrm{kg} /$ day) until sacrifice at 29 days post-injury (dpi). (A) Representative whole perfused brains and cresyl violet-stained brain sections from CCI injured mice treated with either vehicle or Ang-(1-7). (B) Measurement of lesion volume was assessed by cresyl violet histology and plotted; $n=7$ mice/group. Mean \pm standard error of the mean; $* p<0.05$. 
A
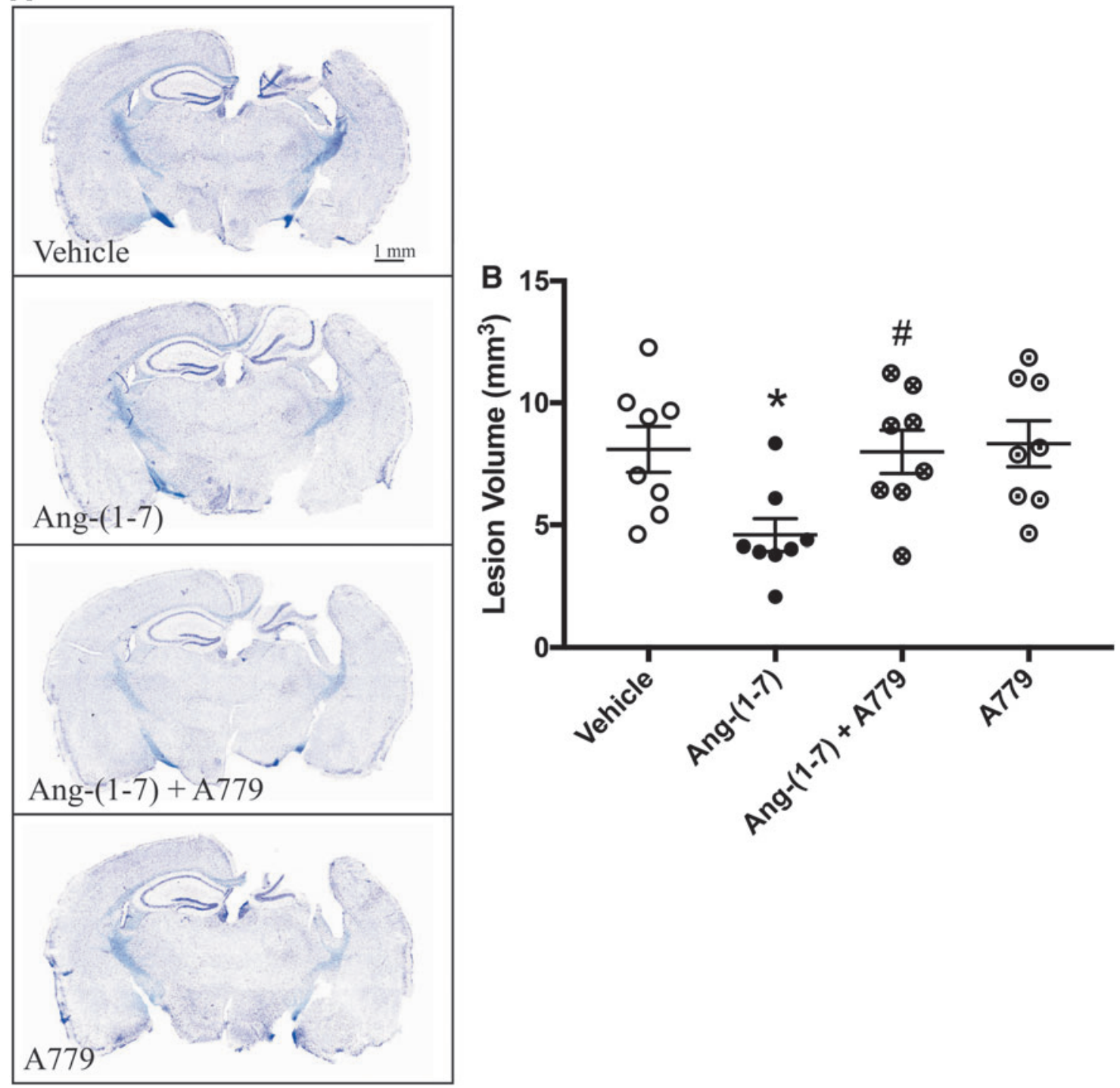

FIG. 9. Dependence of angiotensin-(1-7) [Ang-(1-7)]-mediated protection on MasR signaling. Mice were treated with a continuous subcutaneous infusion of MasR antagonist, A-779 (2.5 mg/kg/day), starting two days prior to injury. Ang-(1-7) (1 mg/kg/day) or vehicle administration was initiated $6 \mathrm{~h}$ after controlled cortical injury (CCI). Mice were sacrificed at 3 dpi. Representative cresyl violet-stained brain sections showing lesion size (A). Quantification of lesion volume in brain sections from all treatment groups (B); $n=8$ mice/group; mean \pm standard error of the mean; ${ }^{*} p<0.05$ compared with vehicle, $\# p<0.05$ compared with Ang-(1-7).

\section{Discussion}

Our study shows that subcutaneous administration of Ang-(1-7) improved physiological, morphological, and functional recovery when administered up to $6 \mathrm{~h}$ following TBI in the mouse. The beneficial effects of Ang-(1-7) treatment included reduction of lesion volume, reduction of activated microglia and astrocytes, neuroprotection, and preservation of microvascular capillary density (Fig. 10). We were able to track the reduction in lesion volume over time in vivo with MRI, and correlate these morphological neuroprotective effects of Ang-(1-7) with improved functional and cognitive recovery. Specifically, Ang-(1-7) prevented acute motor coordination deficits and attenuated long-term learning and memory deficits associated with CCI. Mechanistically, our data indicate that Ang-(1-7) neuroprotection is mediated in a MasR-dependent fashion. Thus, these pre-clinical data suggest that Ang-(1-7) may be a promising therapeutic for the treatment of TBI.
Our data indicate that CCI caused microgliosis, astrogliosis, capillary loss, and neuronal loss at both 3 and 29 dpi. At 3 dpi, microgliosis, but not astrogliosis, was attenuated by Ang-(1-7) treatment in each neuroanatomical region assessed (Fig. 3). By $29 \mathrm{dpi}$, the thalamus was the only region assessed where Ang-(1-7) treatment continued to attenuate microgliosis (Fig. 5). At 29 dpi, the overall microglial response to injury is attenuated in comparison to that at $3 \mathrm{dpi}$, and remains strongest in the thalamus. Therefore, the residual effect of Ang-(1-7) on thalamic microglia, rather than cortical microglia, could simply reflect the ability of the assay to detect a larger reduction in Iba1+ cells. Ang-(1-7) treatment of cultured primary rat microglia can reduce both basal and activated expression of pro-inflammatory cytokines such as interleukin $1 \beta$ and tumor necrosis factor $\alpha$, and inducible nitric oxide synthase. ${ }^{20,27,35}$ Thus, the Ang-(1-7) reduction of microgliosis is likely, at least in part, to be a direct effect of the peptide on microglia. These antiinflammatory effects of Ang-(1-7) on microglia are conserved in vivo 

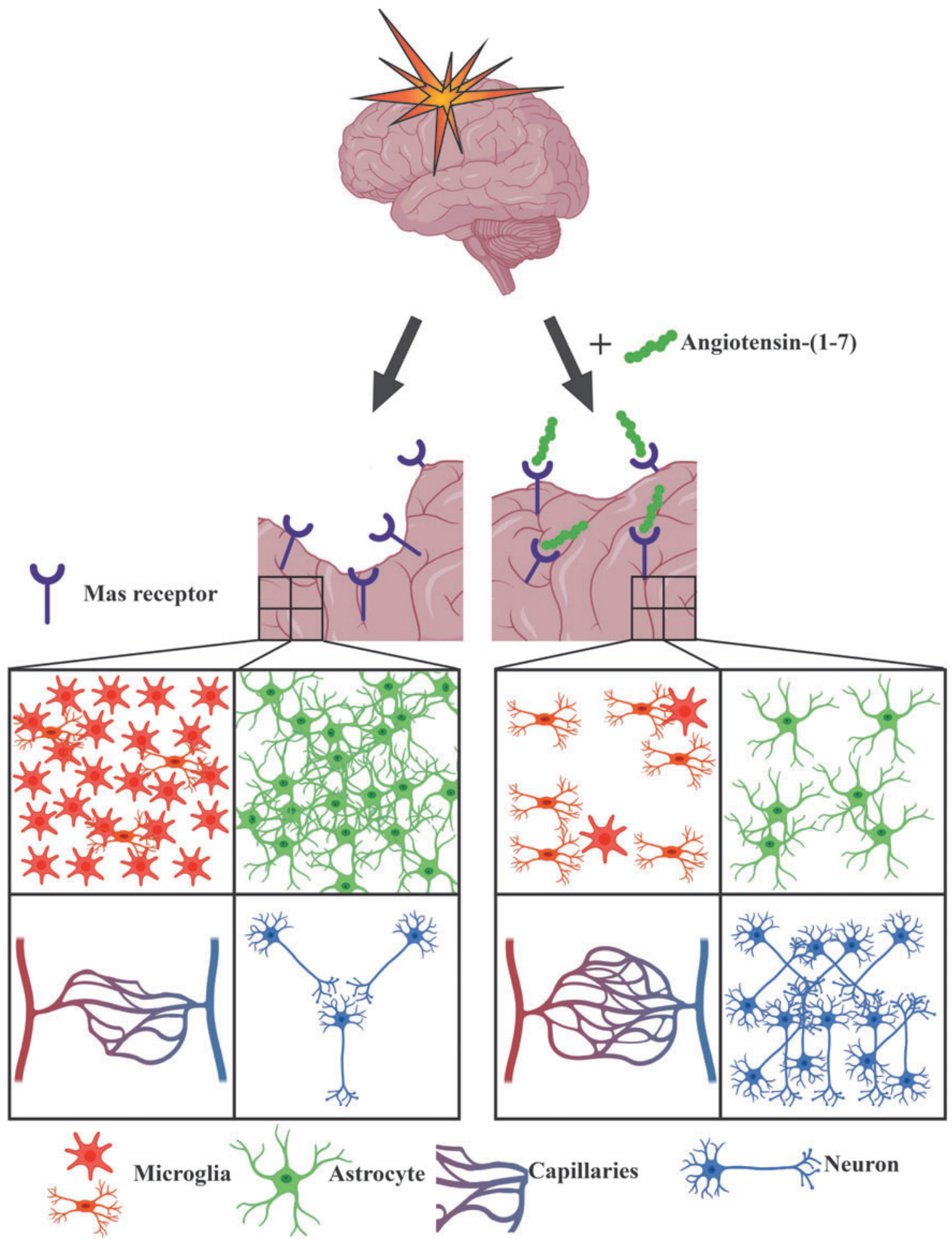

FIG. 10. The effects of angiotensin-(1-7) [Ang-(1-7)] are neuroprotective after traumatic brain injury. Subcutaneous administration of Ang-(1-7) promotes morphological and functional recovery in a mouse model of traumatic brain injury by reducing gliosis and preserving both capillary and neuronal density around the site of injury.

following both ischemic and hemorrhagic stroke. ${ }^{27}$ Our data show that Ang-(1-7) also mediates an attenuation of microgliosis after TBI.

The astroglial response to injury changed over time. There was increased astrogliosis at both 3 and 29 dpi in all three brain regions examined, with the response greater at $29 \mathrm{dpi}$. There also were clear signs of glial scar formation in the peri-lesional cortex at $29 \mathrm{dpi}$
(Fig. 5). Interestingly, and in contrast to the effect on microgliosis, Ang-(1-7) treatment did not affect the degree of reactive astrogliosis at $3 \mathrm{dpi}$, but significantly reduced it at $29 \mathrm{dpi}$ in each neuroanatomical region assessed. The differential ability of Ang-(1-7) to reduce reactive astrogliosis at $29 \mathrm{dpi}$, but not $3 \mathrm{dpi}$, may indicate that different pathways contribute to GFAP induction at these two 
time-points. Thus, Ang-(1-7) may only have efficacy attenuating pathways involved at the later time-point. It would be interesting to determine whether Ang-(1-7) reduces other markers of astrocyte activation with a similar time course.

CCI injury led to significant reduction in neuronal and capillary density in the ipsilateral cortex and thalamus at 3 and 29 dpi (Fig. 4 and Fig. 6). In the ipsilateral thalamus, Ang-(1-7) treatment led to greater neuronal and capillary density after injury than vehicle treatment at $29 \mathrm{dpi}$. MasR is highly expressed in various neuronal populations. ${ }^{26}$ MasR activation acts to promote neuronal survival in vitro during glucose deprivation studies, and in Ang-(1-7)treated mice subject to stroke. ${ }^{23,26,36}$ Ang-(1-7) also has direct beneficial effects on endothelial progenitor and endothelial cells. Exogenous Ang-(1-7) induced vascular repair in a diabetic mouse model, and enhanced the production of endothelial progenitor cells after myocardial infarction. ${ }^{37,38}$ Ang-(1-7) also increased brain capillary density following ischemic stroke in rats when administered intracerebroventricularly or through S.Q. injection (personal communication, Dr. Rick Franklin, Constant Pharmaceuticals, 2017). ${ }^{25}$ Interestingly, the thalamic-specific Ang-(1-7) rescue of neuronal and capillary density at 29 dpi corresponds with the Ang(1-7) mediated attenuation of microgliosis in the same neuroanatomical region, at the same time-point (Fig. 5). Thalamic astrocytic activation is also reduced at $29 \mathrm{dpi}$ (Fig. 5). Therefore, the beneficial effects of Ang-(1-7) on each cell type could be a combination of direct and indirect effects. Taken together, it is likely that Ang(1-7) promotes its neuroprotective phenotype through both direct action on neurons and the cerebrovasculature, as well as by paracrine signaling through astrocytes and microglia.

We do not understand why Ang-(1-7) reduced the cellular consequences of CCI at 29 dpi specifically in the thalamus. The thalamus remains intact after CCI, and may be the closest structurally intact brain region to the lesion. The ipsilateral hippocampus is closer to the impact, but its integrity is not maintained. We were therefore unable to accurately measure immunohistochemical changes in the ipsilateral hippocampus. However, it is probable that Ang-(1-7) treatment also had similar beneficial effects in this region. In fact, various studies have demonstrated a requirement for intact CA3 and CA1 hippocampal fields, as well as intact anterior thalamic nuclei, in order to preserve spatiotemporal memory in the MWM. ${ }^{39-42}$ Thus, the Ang-(1-7) mediated recovery of spatiotemporal learning and memory deficits after TBI, as assessed by the MWM (Fig. 8), suggests a preservation or recovery of both thalamic and hippocampal integrity.

In addition to signaling through the MasR, Ang-(1-7) was recently shown to signal through the MrgD receptor in cell culture. ${ }^{34,43}$ Within the CNS, MasR expression is strongest in cortical and hippocampal neurons, but it is also expressed in vascular endothelium, microglia, and astrocytes. ${ }^{20,44-47}$ Expression of MrgD is much lower than MasR in the CNS, although in this study we did not quantify expression of either receptor. ${ }^{48}$ The antagonist that we utilized, A779, has greater specificity for MasR over MrgD. ${ }^{34}$ Thus, our finding that the Ang-(1-7) mediated reduction in lesion volume can be blocked with A779 (Fig. 9) suggests that this neuroprotective effect of Ang-(1-7) is mediated by MasR signaling.

The beneficial effect of this protective axis of the RAS has been demonstrated in various rodent stroke studies where experimentally increased Ang-(1-7), produced either by activators of ACE2 or through direct Ang-(1-7) intracerebroventricular (I.C.V.) administration, reduces neurological deficits and lesion volume. ${ }^{25,27,28,30}$ In contrast, Ang II signaling through AT1R induces vasoconstric- tion, increases inflammation, and subsequently exacerbates lesion volume following ischemic stroke. ${ }^{49-51}$ Ischemic stroke and TBI share a variety of pathological features. ${ }^{52}$ However, features such as direct cell membrane damage, contusion formation, and primary axotomy are all unique to TBI. ${ }^{52}$ Thus, our finding that Ang-(1-7) administration improves recovery after CCI injury in the mouse extends the potential clinical applications of this peptide.

We designed our study to optimize the translational relevance of these pre-clinical experiments. We found that Ang-(1-7) administration could be started up to $6 \mathrm{~h}$ after the injury, a clinically relevant therapeutic time window, and still have a beneficial effect when evaluated at 3, 10, 24, or 29 dpi (Fig. 3 and Fig. 6-9). Evaluation of later times of administration showed that a $24 \mathrm{~h}$ window between injury and drug administration produced an intermediate effect on lesion volume (Fig. 8). It may therefore be possible to lengthen the beneficial therapeutic time window past $6 \mathrm{~h}$ with a more detailed, highly powered study. We also administered the Ang-(1-7) peptide through S.Q. administration. To our knowledge, ours is the first published study using S.Q. administration of Ang(1-7) to treat CNS injury, instead of an I.C.V. route of administration. ${ }^{53}$ Clinically, S.Q. administration is preferable to I.C.V. administration. Indeed, S.Q. administration of Ang-(1-7) is currently being used in two clinical trials to improve cognitive function following cardiovascular stress (NCT03252093, NCT03159988). Drugs administered S.Q. will need to cross the blood-brain barrier (BBB) to act within the CNS. The significant BBB disruption after CCI allows access into the CNS early after injury. ${ }^{54-56}$ However, in mice after CCI the BBB is reformed relatively quickly, such that by 29 dpi the BBB has predominantly healed. ${ }^{55,57}$ Whether or not Ang(1-7) needs to cross the BBB to influence the CNS is uncertain. Some of the neuroprotective effects of Ang-(1-7) could be directly mediated through microvascular endothelial cells, to which Ang-(17) readily gains access. ${ }^{58}$ Further, in contrast to rodent studies, recent reports suggest that TBI-induced BBB permeability may persist in humans for months to years following injury; thus, drug access to the CNS in human subjects may remain at later stages of injury. ${ }^{59}$

Although our data show distinct beneficial effects of Ang-(1-7) treatment after TBI in this mouse model, there are clearly limitations of our study. We did not monitor the blood pressure of mice in these experiments. Although Ang-(1-7) has vasodilatory actions, it has no net effect on blood pressure in normotensive animals, ${ }^{32,60}$ suggesting that treatment would not lower blood pressure in our mice. If there was an overall reduction in blood pressure with the dose of Ang-(1-7) we used, other data suggests that this could be detrimental to recovery rather than beneficial. Data from the large Impact of Implementing the EMS Traumatic Brain Injury Treatment Guideline clinical trial (NCT01339702) shows a significant increase in mortality in normoxic hypotensive TBI patients compared with normoxic, normotensive TBI patients, even after controlling for multiple potential confounders. ${ }^{61}$ Further, in rodents, there is a deleterious association between acute hemorrhagic hypotension and neurological outcome following TBI. ${ }^{62}$ Thus, we suggest that it is unlikely that Ang-(1-7) reduced blood pressure in our experiments, and very improbable that any potential reduction would be beneficial to recovery. Additional limitations of our study include the relatively young age of the mice that we used (8-10 weeks when injured). It is possible that older animals may respond differently to Ang-(1-7). However, Ang-(1-7) treatment reduced the microglial inflammatory profile in 8-month-old senescence accelerated mice, suggesting that at least some of Ang-(1-7)'s actions may be similar in older mice. ${ }^{63}$ Further experiments will be 
necessary to determine if Ang-(1-7) has efficacy in improving recovery in older mice or in different TBI models.

Various studies have shown discrepancies between histology and MRI. ${ }^{64,65}$ Our histologic analysis was in agreement with that of our MRI, although MRI provided a different, and probably more accurate, assessment of the lesion. The cavitating brain lesion observed under histologic assessment appeared as a herniating lesion in vivo (Fig. 2). This was likely due to increased intracranial pressure following post-injury brain swelling within the skull. ${ }^{66}$ Interestingly, although we did not replace the bone flap after the craniectomy, the small craniectomy window may worsen the lesion by promoting further brain damage in the herniated tissue. This is, at least partially, why current guidelines for the management of severe TBI recommend large $(12 \times 15 \mathrm{~cm})$, rather than small, decompressive craniectomy for emergency cranial decompression. ${ }^{2}$ Nonetheless, Ang-(1-7) administration significantly reduced lesion volume by histologic and MRI analysis at all time-points examined. The ability to utilize a clinically approved imaging modality to measure Ang-(1-7) efficacy shows potential for use as a clinical readout.

In summary, we have shown that subcutaneous administration of Ang-(1-7) up to $6 \mathrm{~h}$ after CCI injury in the mouse is neuroprotective and able to improve functional recovery; likely through a reduction in glial activation and promotion of greater microvascular density. These pre-clinical data show the pleiotropic neurorestorative effects of Ang-(1-7) after TBI and, together with previous studies on the efficacy of ARBs in improving recovery after TBI, suggest that manipulation of the RAS has real potential for the clinical treatment of patients suffering from TBI. ${ }^{11,13}$

\section{Acknowledgments}

This work was supported by a grant from the Department of Defense Centre for Neuroscience and Regenerative Medicine (AJS). We thank Dr. Rick Franklin (Constant Pharmaceuticals) for the gift of the Ang-(1-7) and Dr. Rick Franklin and Professor Thomas Walter for many informative discussions. We are grateful to Dr. Cara Olson for biostatistical consultations and members of the Symes laboratory and Zachary Janatpour's thesis committee for their helpful comments and suggestions.

\section{Author Disclosure Statement}

The opinions and assertions contained herein are the private opinions of the authors and are not to be construed as reflecting the views of the Uniformed Services University of the Health Sciences, the U.S. Department of Defense, or the U.S. Department of the Army.

No competing financial interests exist.

\section{References}

1. Popescu, C., Anghelescu, A., Daia, C., and Onose, G. (2015). Actual data on epidemiological evolution and prevention endeavours regarding traumatic brain injury. J. Med. Life 8, 272-277.

2. Carney, N., Totten, A.M., O'Reilly, C., Ullman, J.S., Hawryluk, G.W., Bell, M.J., Bratton, S.L., Chesnut, R., Harris, O.A., Kissoon, N., Rubiano, A.M., Shutter, L., Tasker, R.C., Vavilala, M.S., Wilberger, J., Wright, D.W., and Ghajar, J. (2017). Guidelines for the Management of Severe Traumatic Brain Injury, Fourth Edition. Neurosurgery $80,6-15$.

3. Diaz-Arrastia, R., Kochanek, P.M., Bergold, P., Kenney, K., Marx, C.E., Grimes, C.J., Loh, L.T., Adam, L.T., Oskvig, D., Curley, K.C., and Salzer, W. (2014). Pharmacotherapy of traumatic brain injury: state of the science and the road forward: report of the Department of Defense Neurotrauma Pharmacology Workgroup. J. Neurotrauma 31, 135-158.

4. Prins, M., Greco, T., Alexander, D., and Giza, C.C. (2013). The pathophysiology of traumatic brain injury at a glance. Dis. Model Mech. 6, 1307-1315.

5. Maas, A.I., Stocchetti, N., and Bullock, R. (2008). Moderate and severe traumatic brain injury in adults. Lancet Neurol. 7, 728-741.

6. Saavedra, J.M. (2005). Brain angiotensin II: new developments, unanswered questions and therapeutic opportunities. Cell. Mol. Neurobiol. 25, 485-512.

7. Saavedra, J.M. (2012). Angiotensin II AT(1) receptor blockers as treatments for inflammatory brain disorders. Clin. Sci. (Lond.) 123, 567-590.

8. Saavedra, J.M. (2011). Angiotensin II AT(1) receptor blockers ameliorate inflammatory stress: a beneficial effect for the treatment of brain disorders. Cell Mol Neurobiol. 32, 667-681.

9. Saavedra, J.M., Benicky, J., and Zhou, J. (2006). Angiotensin II: multitasking in the brain. J. Hypertens. Suppl 24, S131-S137.

10. Saavedra, J.M., Benicky, J., and Zhou, J. (2006). Mechanisms of the Anti-Ischemic Effect of Angiotensin II AT(1) Receptor Antagonists in the Brain. Cell. Mol. Neurobiol. 26, 1099-1111.

11. Villapol, S., Balarezo, M.G., Affram, K., Saavedra, J.M., and Symes, A.J. (2015). Neurorestoration after traumatic brain injury through angiotensin II receptor blockage. Brain 138, 3299-3315.

12. Villapol, S. and Saavedra, J.M. (2015). Neuroprotective effects of angiotensin receptor blockers. Am J Hypertens 28, 289-299.

13. Villapol, S., Yaszemski, A.K., Logan, T.T., Sanchez-Lemus, E., Saavedra, J.M., and Symes, A.J. (2012). Candesartan, an angiotensin II AT(1)-receptor blocker and PPAR-gamma agonist, reduces lesion volume and improves motor and memory function after traumatic brain injury in mice. Neuropsychopharmacology 37, 2817-2829.

14. Xu, P., Sriramula, S., and Lazartigues, E. (2011). ACE2/ANG-(1-7)/ Mas pathway in the brain: the axis of good. Am. J. Physiol. Regul. Integr. Comp. Physiol. 300, R804-R817.

15. Bader, M. (2013). ACE2, angiotensin-(1-7), and Mas: the other side of the coin. Pflugers Arch. 465, 79-85.

16. Chappel, M.C. and Ferrario, C.M. (2006). ACE and ACE2: their role to balance the expression of angiotensin II and angiotensin-(1-7). Kidney Int. 70, 8-10.

17. Vickers, C., Hales, P., Kaushik, V., Dick, L., Gavin, J., Tang, J., Godbout, K., Parsons, T., Baronas, E., Hsieh, F., Acton, S., Patane, M., Nichols, A., and Tummino, P. (2002). Hydrolysis of biological peptides by human angiotensin-converting enzyme-related carboxypeptidase. J. Biol. Chem. 277, 14838-14843.

18. Bosnyak, S., Jones, E.S., Christopoulos, A., Aguilar, M.I., Thomas, W.G., and Widdop, R.E. (2011). Relative affinity of angiotensin peptides and novel ligands at AT1 and AT2 receptors. Clin. Sci. (Lond.) 121, 297-303.

19. Santos, R.A., Simoes e Silva, A.C., Maric, C., Silva, D.M., Machado, R.P., de Buhr, I., Heringer-Walther, S., Pinheiro, S.V., Lopes, M.T., Bader, M., Mendes, E.P., Lemos, V.S., Campagnole-Santos, M.J., Schultheiss, H.P., Speth, R., and Walther, T. (2003). Angiotensin-(17 ) is an endogenous ligand for the G protein-coupled receptor Mas. Proc. Natl. Acad. Sci. U. S. A. 100, 8258-8263.

20. Liu, M., Shi, P. and Sumners, C. (2016). Direct anti-inflammatory effects of angiotensin-(1-7) on microglia. J. Neurochem. 136, 163171.

21. Moore, E.D., Kooshki, M., Metheny-Barlow, L.J., Gallagher, P.E., and Robbins, M.E. (2013). Angiotensin-(1-7) prevents radiation-induced inflammation in rat primary astrocytes through regulation of MAP kinase signaling. Free Radic. Biol. Med. 65, 1060-1068.

22. Souza, A.P., Sobrinho, D.B., Almeida, J.F., Alves, G.M., Macedo, L.M., Porto, J.E., Vencio, E.F., Colugnati, D.B., Santos, R.A., Ferreira, A.J., Mendes, E.P., and Castro, C.H. (2013). Angiotensin II type 1 receptor blockade restores angiotensin-(1-7)-induced coronary vasodilation in hypertrophic rat hearts. Clin Sci (Lond) 125, 449-459.

23. Zheng, J., Li, G., Chen, S., Bihl, J., Buck, J., Zhu, Y., Xia, H., Lazartigues, E., Chen, Y., and Olson, J.E. (2014). Activation of the ACE2/Ang-(1-7)/Mas pathway reduces oxygen-glucose deprivationinduced tissue swelling, ROS production, and cell death in mouse brain with angiotensin II overproduction. Neuroscience 273, 39-51.

24. Hay, M., Vanderah, T.W., Samareh-Jahani, F., Constantopoulos, E., Uprety, A.R., Barnes, C.A., and Konhilas, J. (2017). Cognitive im- 
pairment in heart failure: A protective role for angiotensin-(1-7) Behav. Neurosci. 131, 99-114.

25. Jiang, T., Yu, J.T., Zhu, X.C., Zhang, Q.Q., Tan, M.S., Cao, L., Wang, H.F., Lu, J., Gao, Q., Zhang, Y.D., and Tan, L. (2014). Angiotensin(1-7) induces cerebral ischaemic tolerance by promoting brain angiogenesis in a Mas/eNOS-dependent pathway. Br. J. Pharmacol. 171, 4222-4232.

26. Lee, S., Evans, M.A., Chu, H.X., Kim, H.A., Widdop, R.E., Drummond, G.R., and Sobey, C.G. (2015). Effect of a selective Mas receptor agonist in cerebral ischemia in vitro and in vivo. PLoS One 10 e0142087.

27. Regenhardt, R.W., Desland, F., Mecca, A.P., Pioquinto, D.J., Afzal, A., Mocco, J., and Sumners, C. (2013). Anti-inflammatory effects of angiotensin-(1-7) in ischemic stroke. Neuropharmacology 71, 154 163.

28. Regenhardt, R.W., Mecca, A.P., Desland, F., Ritucci-Chinni, P.F., Ludin, J.A., Greenstein, D., Banuelos, C., Bizon, J.L., Reinhard, M.K., and Sumners, C. (2014). Centrally administered angiotensin-(1-7) increases the survival of stroke-prone spontaneously hypertensive rats. Exp. Physiol. 99, 442-453.

29. Xiao, X., Zhang, C., Ma, X., Miao, H., Wang, J., Liu, L., Chen, S., Zeng, R., Chen, Y., and Bihl, J.C. (2015). Angiotensin-(1-7) counteracts angiotensin II-induced dysfunction in cerebral endothelial cells via modulating Nox2/ROS and PI3K/NO pathways. Exp. Cell Res. 336, 58-65.

30. Bennion, D.M., Haltigan, E.A., Irwin, A.J., Donnangelo, L.L., Regenhardt, R.W., Pioquinto, D.J., Purich, D.L., and Sumners, C. (2015). Activation of the neuroprotective angiotensin-converting enzyme 2 in rat ischemic stroke. Hypertension 66, 141-148.

31. Hamm, R.J. (2001). Neurobehavioral assessment of outcome following traumatic brain injury in rats: an evaluation of selected measures. J. Neurotrauma 18, 1207-1216.

32. Williams, I.M., Otero, Y.F., Bracy, D.P., Wasserman, D.H., Biaggioni, I., and Arnold, A.C. (2016). Chronic angiotensin-(1-7) improves insulin sensitivity in high-fat fed mice independent of blood pressure. Hypertension 67, 983-991.

33. Niesman, I.R., Schilling, J.M., Shapiro, L.A., Kellerhals, S.E., Bonds, J.A., Kleschevnikov, A.M., Cui, W., Voong, A., Krajewski, S., Ali, S.S., Roth, D.M., Patel, H.H., Patel, P.M., and Head, B.P. (2014) Traumatic brain injury enhances neuroinflammation and lesion volume in caveolin deficient mice. J. Neuroinflammation 11, 39.

34. Tetzner, A., Gebolys, K., Meinert, C., Klein, S., Uhlich, A., Trebicka, J., Villacanas, O., and Walther, T. (2016). G-protein-coupled receptor $\mathrm{MrgD}$ is a receptor for angiotensin-(1-7) involving adenylyl cyclase, cAMP, and phosphokinase A. Hypertension 68, 185-194.

35. Shi, P., Grobe, J.L., Desland, F.A., Zhou, G., Shen, X.Z., Shan, Z., Liu, M., Raizada, M.K., and Sumners, C. (2014). Direct proinflammatory effects of prorenin on microglia. PLoS One 9, e92937.

36. Chen, J., Zhao, Y., Chen, S., Wang, J., Xiao, X., Ma, X., Penchikala M., Xia, H., Lazartigues, E., Zhao, B., and Chen, Y. (2014). Neuronal over-expression of ACE2 protects brain from ischemia-induced damage. Neuropharmacology 79, 550-558.

37. Vasam, G., Joshi, S., Thatcher, S.E., Bartelmez, S.H., Cassis, L.A., and Jarajapu, Y.P. (2017). Reversal of bone marrow mobilopathy and enhanced vascular repair by angiotensin-(1-7) in diabetes. Diabetes $66,505-518$

38. Wang, Y., Qian, C., Roks, A.J., Westermann, D., Schumacher, S.M., Escher, F., Schoemaker, R.G., Reudelhuber, T.L., van Gilst, W.H., Schultheiss, H.P., Tschope, C., and Walther, T. (2010). Circulating rather than cardiac angiotensin-(1-7) stimulates cardioprotection after myocardial infarction. Circ. Heart Fail. 3, 286-293.

39. Stackman, R.W., Jr., Lora, J.C., and Williams, S.B. (2012). Directional responding of $\mathrm{C} 57 \mathrm{BL} / 6 \mathrm{~J}$ mice in the Morris water maze is influenced by visual and vestibular cues and is dependent on the anterior thalamic nuclei. J. Neurosci. 32, 10211-10225.

40. Warburton, E.C. and Aggleton, J.P. (1999). Differential deficits in the Morris water maze following cytotoxic lesions of the anterior thalamus and fornix transection. Behav. Brain Res. 98, 27-38.

41. Warburton, E.C., Baird, A.L., Morgan, A., Muir, J.L., and Aggleton, J.P. (2000). Disconnecting hippocampal projections to the anterior thalamus produces deficits on tests of spatial memory in rats. Eur. J. Neurosci. 12, 1714-1726.

42. Redish, A.D. and Touretzky, D.S. (1998). The role of the hippocampus in solving the Morris water maze. Neural Comput. 10, 73-111.
43. Solinski, H.J., Gudermann, T., and Breit, A. (2014). Pharmacology and signaling of MAS-related G protein-coupled receptors. Pharmacol. Rev. 66, 570-597.

44. Freund, M., Walther, T., and von Bohlen und Halbach, O. (2012). Immunohistochemical localization of the angiotensin-(1-7) receptor Mas in the murine forebrain. Cell. Tissue Res. 348, 29-35.

45. Leonhardt, J., Villela, D.C., Teichmann, A., Munter, L.M., Mayer, M.C., Mardahl, M., Kirsch, S., Namsolleck, P., Lucht, K., Benz, V., Alenina, N., Daniell, N., Horiuchi, M., Iwai, M., Multhaup, G. Schulein, R., Bader, M., Santos, R.A., Unger, T., and Steckelings, U.M. (2017). Evidence for heterodimerization and functional interaction of the angiotensin type 2 receptor and the receptor MAS. Hypertension 69, 1128-1135.

46. Martin, K.A., Grant, S.G., and Hockfield, S. (1992). The mas protooncogene is developmentally regulated in the rat central nervous system. Brain Res. Dev. Brain Res. 68, 75-82.

47. Young, D., O'Neill, K., Jessell, T., and Wigler, M. (1988). Characterization of the rat mas oncogene and its high-level expression in the hippocampus and cerebral cortex of rat brain. Proc. Natl. Acad. Sci. U. S. A. 85, 5339-5342.

48. Jackson, L., Eldahshan, W., Fagan, S.C., and Ergul, A. (2018). Within the brain: the renin angiotensin system. Int. J. Mol. Sci. 19.

49. Knecht, K.R. and Leffler, C.W. (2010). Distinct effects of intravascular and extravascular angiotensin II on cerebrovascular circulation of newborn pigs. Exp. Biol. Med. (Maywood) 235, 1479-1488.

50. Nishimura, Y., Ito, T., Hoe, K., and Saavedra, J.M. (2000). Chronic peripheral administration of the angiotensin II AT(1) receptor antagonist candesartan blocks brain AT(1) receptors. Brain Res. 871, $29-38$.

51. Walther, T., Olah, L., Harms, C., Maul, B., Bader, M., Hortnagl, H., Schultheiss, H.P., and Mies, G. (2002). Ischemic injury in experimental stroke depends on angiotensin II. FASEB J 16, 169-176.

52. Bramlett, H.M. and Dietrich, W.D. (2004). Pathophysiology of cerebral ischemia and brain trauma: similarities and differences. J. Cereb. Blood Flow Metab. 24, 133-150.

53. Bennion, D.M., Haltigan, E., Regenhardt, R.W., Steckelings, U.M. and Sumners, C. (2015). Neuroprotective mechanisms of the ACE2angiotensin-(1-7)-Mas axis in stroke. Curr. Hypertens. Rep. 17, 3.

54. Alluri, H., Shaji, C.A., Davis, M.L., and Tharakan, B. (2018). A mouse controlled cortical impact model of traumatic brain injury for studying blood-brain barrier dysfunctions. Methods Mol. Biol. 1717, $37-52$.

55. Baskaya, M.K., Rao, A.M., Dogan, A., Donaldson, D., and Dempsey, R.J. (1997). The biphasic opening of the blood-brain barrier in the cortex and hippocampus after traumatic brain injury in rats. Neurosci. Lett. 226, 33-36.

56. Shapira, Y., Setton, D., Artru, A.A., and Shohami, E. (1993). Bloodbrain barrier permeability, cerebral edema, and neurologic function after closed head injury in rats. Anesth. Analg. 77, 141-148.

57. Main, B.S., Villapol, S., Sloley, S.S., Barton, D.J., Parsadanian, M., Agbaegbu, C., Stefos, K., McCann, M.S., Washington, P.M., Rodriguez, O.C., and Burns, M.P. (2018). Apolipoprotein E4 impairs spontaneous blood brain barrier repair following traumatic brain injury. Mol. Neurodegener. 13, 17.

58. Sullivan, J.C., Rodriguez-Miguelez, P., Zimmerman, M.A., and Harris, R.A. (2015). Differences in angiotensin (1-7) between men and women. Am. J. Physiol. Heart Circ. Physiol. 308, H1171-H1176.

59. Hay, J.R., Johnson, V.E., Young, A.M., Smith, D.H., and Stewart, W. (2015). Blood-brain barrier disruption is an early event that may persist for many years after traumatic brain injury in humans. J. Neuropathol. Exp. Neurol. 74, 1147-1157.

60. Santos, R.A. (2014). Angiotensin-(1-7). Hypertension 63, 1138-1147.

61. Spaite, D.W., Hu, C., Bobrow, B.J., Chikani, V., Barnhart, B., Gaither J.B., Denninghoff, K.R., Adelson, P.D., Keim, S.M., Viscusi, C., Mullins, T., and Sherrill, D. (2017). The effect of combined out-ofhospital hypotension and hypoxia on mortality in major traumatic brain injury. Ann. Emerg. Med. 69, 62-72.

62. Schutz, C., Stover, J.F., Thompson, H.J., Hoover, R.C., Morales, D.M., Schouten, J.W., McMillan, A., Soltesz, K., Motta, M., Spangler, Z., Neugebauer, E., and McIntosh, T.K. (2006). Acute, transient hemorrhagic hypotension does not aggravate structural damage or neurologic motor deficits but delays the long-term cognitive recovery following mild to moderate traumatic brain injury. Crit. Care Med. 34, 492-501. 
63. Jiang, T., Xue, L.J., Yang, Y., Wang, Q.G., Xue, X., Ou, Z., Gao, Q., Shi, J.Q., Wu, L., and Zhang, Y.D. (2018). AVE0991, a nonpeptide analogue of Ang-(1-7), attenuates aging-related neuroinflammation. Aging (Albany NY) 10, 645-657.

64. Ditor, D.S., John, S., Cakiroglu, J., Kittmer, C., Foster, P.J., and Weaver, L.C. (2008). Magnetic resonance imaging versus histological assessment for estimation of lesion volume after experimental spinal cord injury. Laboratory investigation. J. Neurosurg. Spine 9, 301-306.

65. Le Nobin, J., Orczyk, C., Deng, F.M., Melamed, J., Rusinek, H., Taneja, S.S., and Rosenkrantz, A.B. (2014). Prostate tumour volumes: evaluation of the agreement between magnetic resonance imaging and histology using novel co-registration software. BJU Int 114, E105E112.
66. Sahuquillo, J. and Arikan, F. (2006). Decompressive craniectomy for the treatment of refractory high intracranial pressure in traumatic brain injury. Cochrane Database Syst. Rev. CD003983.

Address correspondence to: Aviva J. Symes, PhD Department of Pharmacology and Molecular Therapeutics Uniformed Services University 4301 Jones Bridge Road Bethesda, MD 20814

E-mail: aviva.symes@usuhs.edu 